\title{
LE VOYAGE DE RETOUR
} A VIAGEM DE RETORNO

Camila Rodrigues Moreira Cruz ${ }^{1}$ 


\section{Resumo}

Esse artigo narra os últimos meses de uma estada de nove anos em território francês. A trajetória de uma artista e pesquisadora em artes visuais são aqui confrontadas à sua experiência exílica, vinculadas ao estudo do eu, ao reconhecimento do outro na formação do sujeito. À partir da análise de obras de artistas e obras pessoais, 0 texto confrontará história de vida, retratos e autorretratos, biografias e autobiografia vinculados à pesquisa teórica em torno da experiência do exílio, segundo Alexis Nouss e Walter Benjamin.

\section{Résumé}

Cet article raconte les derniers mois d'un séjour de neuf ans en territoire français. L'histoire d'une artiste et chercheuse est ici confrontée à son expérience exilique, liée à l'étude du moi, à la reconnaissance de l'autre dans la formation du sujet. À partir de l'analyse des œuvres d'artistes et œuvres personnelles, le texte va confronter l'histoire de vie, portrait et autoportrait, biographies et autobiographies, liés à la recherche théorique autour de l'expérience exilique selon Alexis Nouss et Walter Benjamin.

Palavras-chave: Exilio. Arte. Partida. Mots clé: Exil. Art. Départ. l'autre. Sujet. Outro. Sujeito.

ISSN: 2175-2346 


\title{
1 Introduction
}

Cet article s'articule autour de l'analyse de la mémoire et d'un corps qui a connu l'exil, le corps-exilique. Il part de l'analyse de mes œuvres, ainsi que d'œuvres d'autres artistes, afin de mettre à l'épreuve une recherche théorique. Cela nous amène à interroger et comprendre le processus exilique que j'ai vécu lorsque j'ai quitté le Brésil pour venir en France. Pourquoi suis-je partie? La raison essentielle de mon départ, il ne faut pas craindre de le dire, était de fuir mon passé ainsi que les expériences vécues dans mon pays pour arriver enfin sur un terrain vierge. Mais je me suis alors exilée dans ma conscience. Ma réflexion se poursuit autour du concept établi par Alexis Nouss, l'exiliance, dont il explique:

\begin{abstract}
Noyau existentiel commun à toutes les expériences de sujets migrants, quelles que soient les époques, les cultures et les circonstances qui les accueillent ou les suscitent, l'exiliance se décline en condition et conscience, les deux pouvant ne pas coïncider : se sentir en exil sans l'être concrètement; l'être concrètement sans se sentir en exil. ${ }^{1}$
\end{abstract}

Je suis une exilée et, en tant que telle, considérée comme quelqu'un qui expérimente et porte en elle un double approche culturelle, celle de ses origines et celle du pays où j'ai cherché accueil. J'essaye de m'installer mais il n'y a pas, toujours selon Alexis Nouss, de lien social sans perception de la différence. Ce changement a provoqué petit à petit un refoulement de mes recherches et mes œuvres : je suis à nouveau sur le point de prendre l'avion car je dois retourner dans mon pays d'origine. Mais comment envisager un retour lorsque son pays natal devient la proie de l'intransigeance?

À mi-chemin, j'ai vécu la froideur de la violence, le sentiment d'impasse dont fait l'expérience un habitant illégitime du territoire; j'ai indirectement vécu des attentats meurtriers, dont je me croyais à l'abri mais qui, du fait de leur proximité, m'ont frappée et poussée à faire demi-tour. Le retour est impossible car le départ restera éternel. Ainsi après l'exil, on doit affronter le post-exil; le point d'arrivée sera un nouveau point de départ. Or, partir est un acte difficile à accomplir lorsqu'on n'est pas encore arrivé à destination. Le point final, le lieu d'accueil n'existe pas; il est aussi transitoire que le désir de partir. La reconnaissance de ce processus exilique pousse le sujet à découvrir, à partir du retour vers son passé, où se place son corps créateur, celui-là même qui questionne son altérité intime.

\section{Un regard exilique}

J'ai reçu une invitation à une exposition huit mois avant d'y aller en France. J'ai alors créé Ranger (2008) une série de 9 dessins. J'étais en train de préparer mon déménagement; il fallait vider les tiroirs, faire les valises pour partir. La cicatrice du harcèlement que j'avais subi commençait à se former. Au milieu de ce processus de rupture et de guérison, j'ai décidé d'ouvrir l'armoire où j'avais placé les objets gardés

1 NUSELOVICI (NOUSS). A. Exiliance : condition et conscience, FMSH-WP-2013-44, septembre 2013, p. 4. Disponível em: < halshs-00861246 https:// halshs.archives-ouvertes.fr/halshs-00861246>. Acesso em : 30 mai 2018. 
avec les nouvelles expériences douloureuses. L'invitation concernait une exposition collective de dessin. Il me fallait donc transposer toutes ces choses matérielles en lignes et en formes, en deux dimensions sur du papier vierge et blanc. J'ai l'habitude de garder des choses comme des petits objets trouvés ou utilisés, des morceaux de tissu, des bouts de papier, des fils, des invitations, etc. En fouillant mes affaires, j'ai trouvé des filets de tissus dont étaient faites les chemises de mon père, j'ai trouvé du velours, des fils, des clefs. Alors j'ai tout mis dans mes dessins. Pour cette œuvre, les objets sont restés immaculés sur le dessin, ils ont fait des formes et des assemblages liés à la construction d'un nouveau réceptacle pour mes souvenirs.

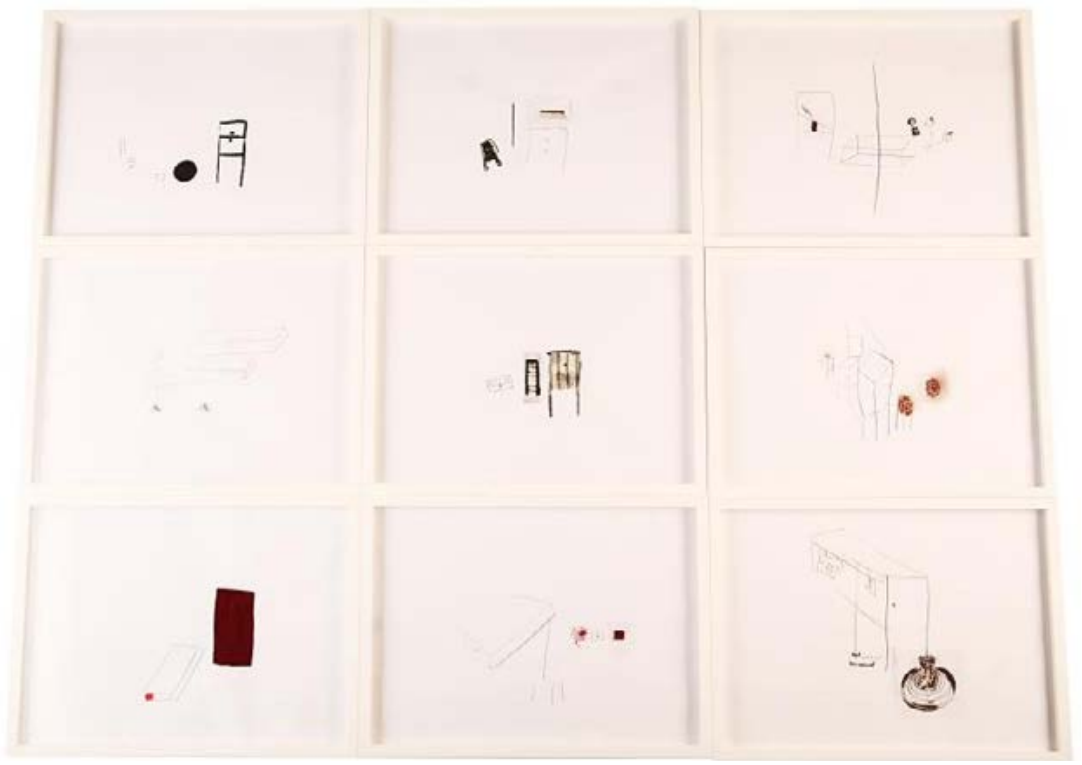

Fig. 1 - Camila Moreira, Ranger, 2008. Série de 9 dessins. Collection Musée d'Art Contemporain Dragão do Mar- CE.

Aujourd'hui, dix ans après cette exposition, avec la distance d'un regard éloigné par le temps et l'espace, je vois que l'œuvre exprime l'attachement à l'objet au moment du départ. Les objets transportés en exil avec l'exilé donnent vie à ses racines, à ses expériences. Ils donnent un corps à son passé, à son histoire. Ils sont les documents d'une mémoire construite et amenée avec lui. L'exilé a besoin de leur présence pour transporter avec lui son existence car au moment de la séparation, quand le manque se manifestera, il pourra y puiser des forces pour lutter. Or il est impossible de tout transporter et il faut laisser sur place la majeure partie de nos biens. Alors on s'attache à de petites choses, à des objets transportables qui seront déterritorialisés comme l'est un corps arraché de sa mère.

Quelle serait l'image créée/révélée par les objets gardés? Comment reconstruire, donner un corps à l'expérience? Il faut que l'objet puisse rester vivant car c'est lui qui produit la réminiscence en moi. Remontant le fil de ma généalogie et des femmes de ma famille auxquelles je suis liée/attachée, j'aperçois dans mes œuvres la présence constante de leur écho sur mon existence. Je pensais à nos blessures, à nos corps déplacés et migrants; je pense aux choses transmises, aux objets conservés. "Réflexion faite, une plaque en vaut bien une autre. D'un esclavage à une extermination, qu'importe la victime, noire ou juive, pourvu que l'histoire, parfois, se souvienne de ceux qu'elle accepta de voir disparaître." (NOUSS, 2010, p. 25). 
L'histoire racontée et consignée des barbaries telles que, en premier lieu la Shoah, la dissémination et la colonisatrice des indiens au Brésil, les conflits en Orient, la guerre en Syrie, les immigrés en fuite... Toutes les calamités que l'homme s'inflige à lui-même survivent quelque part en moi. Quand je pense à mon ancêtre indienne et aux milliers de femmes violées à l'instant où j'écris ces mots, je me demande quelle est l'histoire que l'on laisse disparaître!

Quelles sont la parole possible, la parole responsable, celle qui oserait défier le silence et s'y substituer, la parole juste? Ce ne peut être qu'une juste parole, celle dont nous sommes justiciables envers ceux-là qui ne peuvent plus répondre ni questionner. La parole qui ne se contente pas d'exprimer l'angoisse ou le deuil, mais qui parvient à se faire entendre des disparus, qui façonne et constitue leur écoute, celle-ci étant alors la forme de leur réponse (NOUSS, 2010, p. 28).

Comme le poète Paul Celan qui a tenté d'aborder par son écriture les ténèbres qui l'envahissaient après qu'ils avaient envahi l'Europe, cette parole, transmise au corps ou qui émane de lui, arrive comme le cri endormi dans mon corps contre la violence infligée à la femme et à la place de celles qui sont mortes en silence. L'objet de l'exilé, l'objet qui reste sur place comme celui qui est emporté, seront les témoins d'une vie vécue, quittée et transposée. " Comme une Blessure. Comme une douleur historique aussi peut-être. Comme le rappel, enfin et sans doute, que l'immortalité est un mirage, et que nous appartenons à " notre âge ", " l'âge du monde " (BAQUÉ, 2015, p. 87).

Ces dessins appartiennent ainsi à l'époque où ils furent tracés, à cette époque où mon corps luttait contre sa finitude mais désirait aussi l'évanouissement de sa douleur. Ils sont les témoins de mes blessures, du silence rompu par mon corps désespéré et épuisé de souffrir.

L'œuvre d'Anselm Kiefer, Für Paul Celan: Aschenblume. (Pour Paul Celan, Fleur de cendre, 2006), est l'une des œuvres que l'artiste a dédiées au poète juif romain de langue allemande, Paul Celan. Témoin et victime de la Shoah (ses parents sont morts dans des camps nazis et lui-même a subi l'internement en camp de travail forcé), Paul Celan sera l'un de ceux qui tenteront par leur écriture de dire l'irreprésentable du génocide. En écho à l'écriture de Paul Celan, l'œuvre d'Anselm Kiefer fait référence à un espace de désolation. Des livres (réels) brûlés et consumés sont insérés sur la toile comme des cadavres dispersés sur le terrain. La couleur dominante est un blanc hivernal, le blanc du calme et du silence de la mort après le génocide. " Là où l'on brûle des livres, on finira par brûler des hommes." (HEINE, in: BOUHOURS, 2015, p. 202).

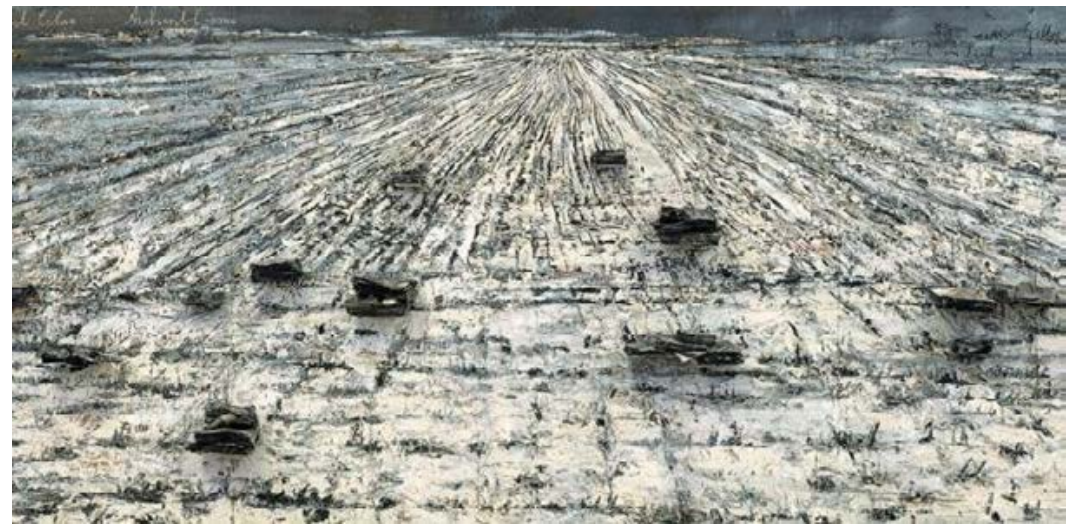

Fig. 2 - Anselm Kiefer, Für Paul Celan: Aschenblume (Pour Paul Célan, Fleur de cendre), 2006, Collection Particulier. 
Dans ces champs d'Europe centrale où on a brûlé des hommes, il faut faire naître l'espoir des cendres dispersées au vent. Là où chacun fait sa traversée solitaire, où la conscience se bat dans un corps lui-même menacé, il faut rompre l'exiliance, il faut donner la vie. Anselm Kiefer peint le terrain des corps errants, soit par leur cendres qui, mêlées à la neige et aux sillons de la terre, hantent le lieu, soit par ces marches vers l'inconnu, qui ne mènent nulle part, sans destin et sans bagage, où l'individu destitué de son identité n'est plus qu'un corps violenté et souffrant.

L'approche de mon œuvre reste certaine. Sur les dessins de Ranger, qui flottent dans l'espace vide du papier blanc qui les entoure, repose l'attente du déplacement que mon corps était sur le point de faire. Les objets restent solitaires, dispersés sur chaque feuille comme des points immobiles. Ils sont symboles d'une mémoire « mise en valises », déposée dans le subconscient et emportée avec soi dans l'exil éminent.

L'exil est une expérience unique dans les registres du vivant qui consiste à pouvoir intégrer dans une existence cet avant/après qui, dans l'épreuve de la mort de l'autre, est expérience impossible, car la césure est soit souffrance absolue, en deçà de l'expérience, soit dépassement amnésique, au-delà de l'expérience, invivable dans les deux cas (NOUSS, 2015, p. 99-100).

Le regard posé sur les objets et leurs formes trace le contour des souvenirs attachés à leur présence. L'objet amené en exil est aussi un objet migrant, déraciné et étranger. Pour lui aussi, il faudra trouver une place, compter sur sa survivance. Figée dans les dessins, immortalisée par la création d'une nouvelle forme rendue possible grâce à l'art, l'âme du sujet migrant se déplacera soulagée, accompagnée par la présence de l'autre qui l'a aidée à se construire. Ranger ces dessins et ces objets fut aussi pour moi une façon de ranger mes souvenirs, de donner une place à ma mémoire et d'orienter le regard du spectateur sur mon corps blessé. Tout cela, avant mon départ.

\section{Lieu de départ, lieu d'accueil}

Je voudrais aborder ici le voyage à proprement parler. C'est pour l'évoquer que, en 2013, j'ai pensé et réalisé Voyage d'exil. Cette vidéo de 1'07" présente le déplacement de mon corps à travers l'océan, entre ma maison natale et mon lieu d'exil. Après cinq ans en France, après avoir vécu le mal du pays, la solitude et la présence en moi sans relâche du désir du retour, j'étais face à la prise de conscience exilique. J'avais survécu au départ, à la traversée et à l'arrivée, mais je ne savais pas où j'étais. J'ai pris des vacances pour aller à Barcelone, un lieu neutre, une sorte de nulle part entre mon pays et la France, au bord des eaux de l'Atlantique. Je me suis postée debout face à la mer et je l'ai abordée du bout des pieds car je ne sais pas nager. J'ai essayé de suivre le mouvement des vagues : elles venaient vers moi, je reculais; j'allais vers les vagues, elles reculaient. Ce moment a duré et plus le vent forcissait, plus le son des voix des enfants qui parlaient une langue que je ne comprenais pas s'intensifiait, plus j'ai pris le temps de construire sur mon corps le voyage-scission commencé en 2008 , l'année de mon départ. 


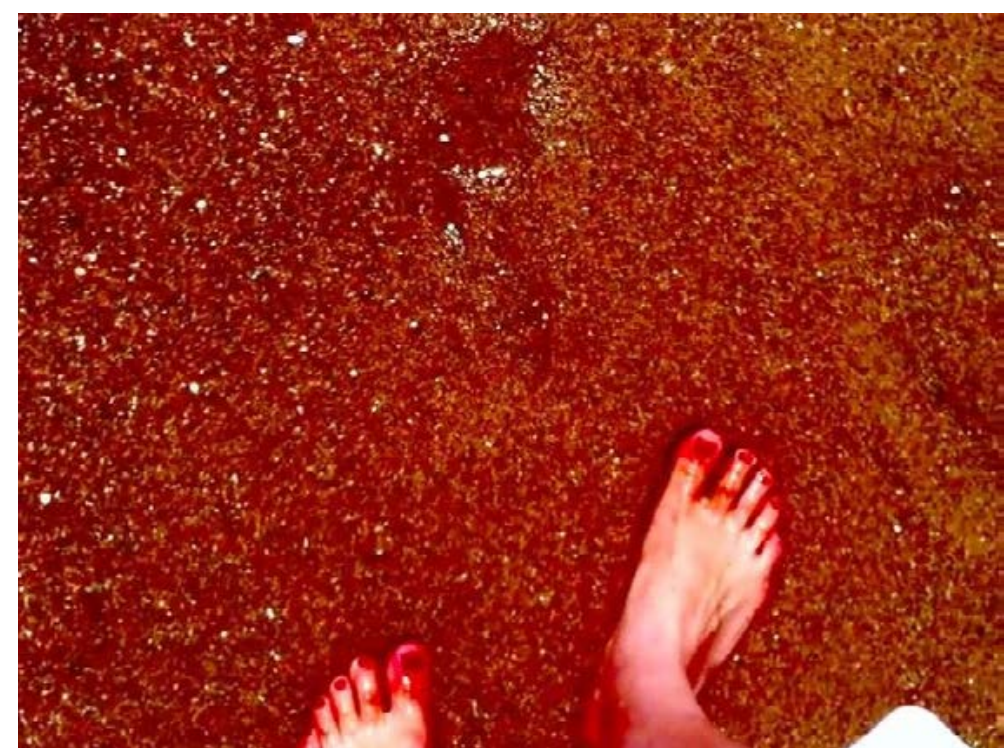

Fig. 3 - Camila Moreira, Voyage d'exil, 2013. Crous Beaux Arts, Paris-France.

Pablo Neruda écrit à propos de l'exil, tu traverses la terre, et ce n'est que la terre. Oui, on ne trouve rien d'autre que la terre dans le nouveau lieu exilique. On compte quatre étapes de l'exil. La plupart des personnes arrivent à les accomplir toutes, d'autres restent naufragées à mi-chemin.

La première étape, c'est le départ. Fils du désespoir, parfois pensé longtemps à l'avance, il arrive comme une lame qui emporte de son tranchant le lieu quitté, la maison natale, la terre de l'origine et des racines. C'est la douleur du déracinement nécessaire : voilà, tu as quitté ton lieu. La deuxième étape, c'est la traversée. Elle peut être destructrice, par la mer qui engloutit ou l'avion qui chute. Certains, arrêtés avant, ne parviennent pas à traverser la frontière. Pendant la traversée tu es dans l'œil du cyclone : ton corps est endormi, anesthésié de ce que tu ne peux éprouver tellement ça fait mal. Tu es devant l'angoisse, l'espoir, le désir, la peur, le doute. Tu es hors de ton territoire, en chemin, tu n'appartiens à personne. Tu es sur la mer, jeté à la dérive par les forces de la nature. Tu es là, dans le non-lieu de passage. Tu prends momentanément ta place, sans tes affaires, et tu te laisses conduire par d'autres jusqu'au lieu que tu as choisi. Puis tu quittes aussi cette place, qui est transitoire car elle appartient au chemin. Certains survivent à ce cataclysme; j'ai survécu.

La troisième étape, c'est l'arrivée. D'abord il y a la surprise de trouver la terre qui, oui, n'est que de la terre et non le territoire tant fantasmé. C'est un nouveau lieu. Voilà, tu y es. Et tout de suite après la prise de conscience que tu n'es pas d'ici. Le grain de cette terre là ne fait pas partie de ton corps et tu restes comme un bateau à la dérive. Il faut trouver ta place, une langue à toi, remplie d'accent, entre la tienne et la nouvelle. Il faut bien se nourrir mais tout ce que tu manges te paraît sans goût. Tu vas finir par t'habituer, par aimer, par faire ici des racines à toi. À cette terre tu donneras tes enfants qui vont marcher sur son grain sans laisser de traces car leur corps, léger comme une plume, comme leurs origines, restera méconnu.

La quatrième étape serait le retour. Oui, je dois quitter le territoire, la terre qui a nourri mes enfants. Je dois partir. Mais pour aller où? Mon pays n'est plus le même. La guerre continue, la lutte et le désespoir l'envahissent. Pourtant mes racines sont 
là-bas, tout comme ma famille et la terre qui a formé mon corps. Et puis aussi j'aperçois maintenant ces petites racines qui poussent dans la terre d'accueil, qui sera donc lui aussi un lieu de départ? Ainsi donc le lieu d'arrivée n'existe pas? Alors lui aussi est transitoire et éphémère? Il existe avant de partir, avant la rencontre, avant l'immersion. Ensuite tout se mélange, tout sera rupture, tout fera désespoir. L'exilé sera l'éternel prisonnier de lui-même; l'exil demeure ses veines, son corps, sa conscience. Je porte l'exil en moi où que je sois, où que j'aille et où que je retourne.

L'œuvre de Louise Bourgeois m'invite une fois de plus à associer à propos du lieu quitté, de la maison natale restée de l'autre côté de l'océan, au passé qui demeure présent. Je voudrais évoquer l'œuvre Cell (Choisy) (1990-1993). L'œuvre se présente sous la forme d'une cage qui renferme, sculptée aux proportions dans un marbre rose, la maison d'enfance de l'artiste, dans laquelle elle vécut entre 1912 et 1915. Cette maison était située en France au numéro 4, avenue de Villeneuve-Saint-Georges à Choisy-le-Roi. La cage est surmontée une guillotine dont le couperet est suspendu et prêt à tomber. " Selon l'artiste, même si celle-ci montre que " les gens se guillotinent à l'intérieur de leur famille", elle symbolise avant tout « le passé qui est guillotiné par le présent. [...] La peur est un état passif, et l'objectif c'est d'être actif et de prendre le contrôle, d'être vivant ici et maintenant. Le mouvement se fait du passif vers l'actif, car si le passé n'est pas nié dans le présent, on ne vit pas "(BERNADAC; STORSVE, 2008, p. 78).

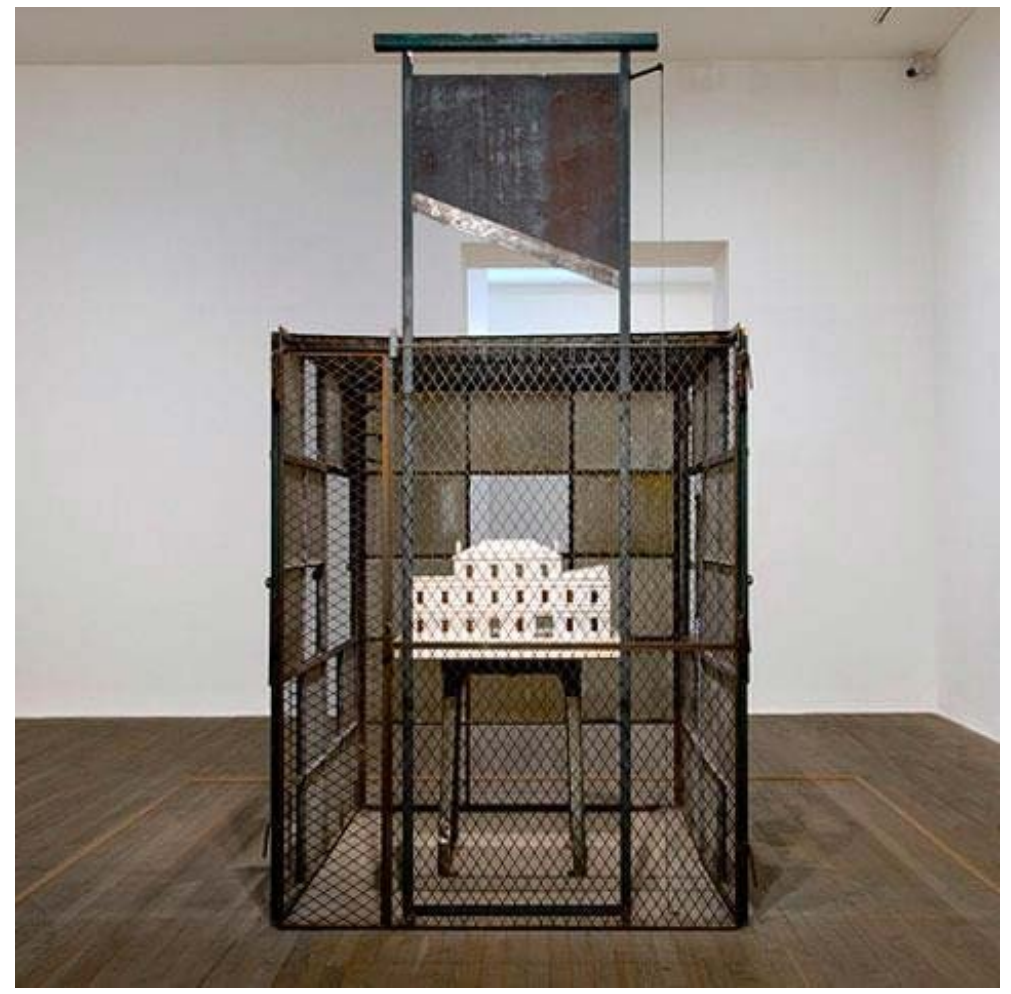

Fig. 4 - Louise Bourgeois, Cell (choisy), 1990-1993, métal, verre, marbre, 302,3 × 368,3 x 304,8 cm, Ydessa Hendeles Art Fondation, Toronto.

Cell (Choisy) est une œuvre de vieillesse, l'enfance de l'artiste est très loin derrière elle; le passé passif y est devenu un présent actif. Je m'interroge : pourquoi, des années après le départ et sur un autre territoire, revient-on toujours au passé, au lieu quitté, à la maison natale? Pourquoi les racines qui nous guillotinent, les blessures de nos genèses sont-elles toujours niées au présent? La maison de Choisy, détruite lorsque 
Louise Bourgeois en fait une œuvre, est dans Cell comme idéalisée : douce, taillé dans un marbre rosé, soigneusement et exactement reproduite. L'amour reste figé et intact.

Dans Voyage d'exil, je suis vêtue d'une robe blanche et je cherche à récupérer mes souvenirs au contact de cette eau qui me sépare de mes origines. Le blanc devient la couleur de la pureté virginale, d'un amour laissé avec les fondations d'une maison d'enfance. Je pensais que je pourrais ainsi mettre en ordre la souffrance, faire un nœud sur l'amour guillotiné d'une vie coupée comme il faut clamper le cordon ombilical coupé : une nécessité pour survivre.

La souffrance est le sujet qui me préoccupe. (...) On ne peut pas nier l'existence des souffrances. Je ne propose pas de remèdes ni d'excuses. Je veux simplement les observer et en parler. Je sais que je ne peux pas rien faire pour les éliminer ni les supprimer. Je ne peux pas les faire disparaître; elles sont là durablement. (...) À quel moment la souffrance émotionnelle devient-elle physique? À quel moment la souffrance physique se fait-elle émotionnelle? $C^{\prime}$ 'est un cercle en révolution sans fin. La souffrance peut survenir à n'importe quel point et aller dans l'une ou l'autre direction (BOURGEOIS, 2007, p. 213).

Voyage d'exil exprime mes inquiétudes quant à cette souffrance déplacée, migrée, déterritorialisée mais toujours présente en mon corps. Je crois désormais, comme Louise Bourgeois, qu'elle ne possède ni remèdes ni excuses. Le voyageur en exil la transporte dans ses valises car elle est incrustée dans sa chair. La conscience, désireuse d'oubli, ne peut rien contre sa présence. C'est la trace imprimée sur la vie virginale, inscrite dans le passé et transférée au présent de chaque être. C'est la direction indiquée par les souffrances sur un chemin qu'il ne faut pas craindre de parcourir, dont on ne peut oublier qu'il a été ouvert et qui, finalement, nous maintient vivants.

Tu quitteras toutes les chères choses

plus tendrement tenues; tel est le dard

que décoche premier l'arc de l'exil.

tu sauras comme il a saveur de sel

le pain d'autrui, et comme est dur chemin

l'autrui perron à gravir ou descendre. (DANTE, 1976 :1520 in : NOUSS (2015), p. 139).

\section{L'objet exilique et l'altérité intime}

Cette démarche vers la rencontre intime faite avant que le temps n'efface irrémédiablement la marque des expériences vécues sera matérialisée par l'objet, par l'objet exilique. Qu'est-ce qu'on peut amener avec soi quand on part en exil? Il arrive un moment où il faut faire un choix et ne pas mettre plus dans la valise que le poids supportable par nos épaules. En 2013, je me suis trouvée face à mes objets d'exil. J'avais en effet réussi à emporter quelques objets dans la soute de l'avion, mélangés à mes bagages, dans mes vêtements. Confrontés à ces questions que j'ai me posais, ils ont pris toute leur signification. D'où suis-je venue? De quelle origine suis-je? Cet ensemble d'objets qui me correspondait me déchiffrait, me tuait, et aussi me faisait vivre. C'est à cette époque que j'ai réalisé Langage, une installation qui comprend deux objets que j'ai créés : une cage remplie de plumes noires et le prototype d'une 
langue en tissu rouge. Je les ai désignés comme mes objets d'exil. La langue représente le territoire d'accueil; la cage symbolise l'origine quittée et pourtant emportée. Fabriquée en acier abimée et rouillée, elle est garnie de plumes noires. Suspendue par une chaîne en métal doré, elle reste fermée. Au-dessous, il y a aussi des plumes noires avec, au milieu, une unique plume blanche qui repose parmi les autres. L'ensemble est la matérialisation d'une expérience exilique.

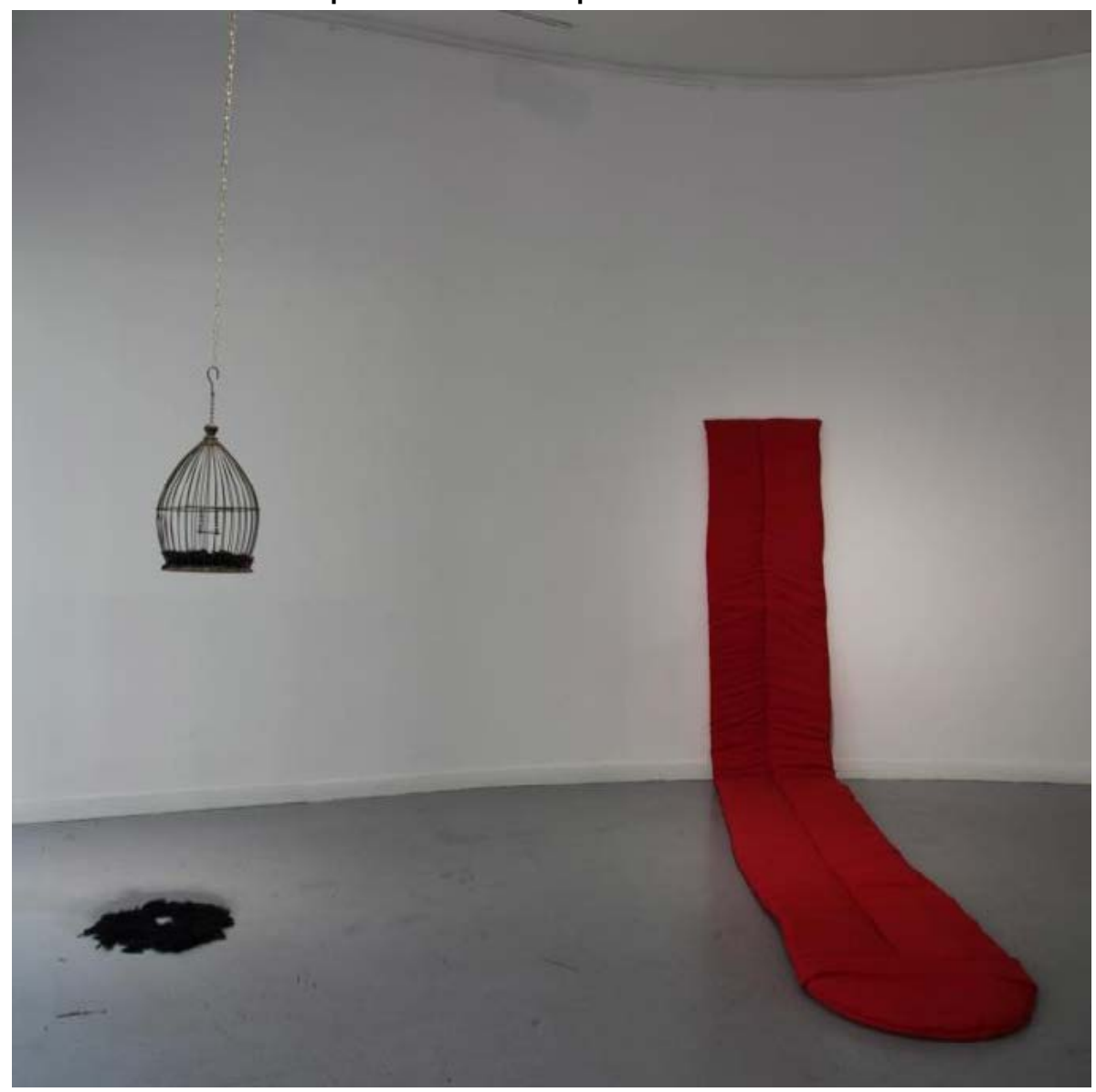

Fig. 5 - Camila Moreira, Langage, 2013. CROUS Beaux Arts-Paris, França.

L'objet, en tant qu'il qui unit le sujet à sa mémoire et à son passé, est ici posé comme substitut. La cage rend compte de mon statut d'étrangère en me présentant comme un oiseau qui souhaite voler pour s'enfuir. Mais l'espèce de cet oiseau noir n'existe pas sur la terre de destination. Il y est étranger et donc étrange. Il a été plumé et doit être imaginé dans toute sa nudité. Son absence doit être comprise comme l'affirmation de sa résistance, de son exil intérieur comme cette plume blanche, fragile parmi les autres mais féroce dans sa terre d'exil. L'oiseau noir n'emmène dans son voyage que ce que son bec peut transporter parce qu'il sait bien que s'il a besoin de chanter, tout tombera par terre. Il doit donc choisir.

Face à la traversée éminente, au bord du vide, ensuite une fois l'élan pris, le corps devient flottant, comme délesté de toute antériorité, y compris les chaudes palpitations de sa mémoire et de sa vie. Il est cet oiseau qui doit voler entre les trous d'air et les tourbillons, entre la plaie à vif de la séparation et la nébuleuse que représente encore la terre d'accueil, dont on ne maîtrise que son propre désir de la connaître et de s'y réfugier. Mais quand enfin le sol approche, où il va pouvoir se poser, il n'y a plus 
une plume sur son corps. Sa nudité la laisse en prise aux cauchemars qui l'attaqueront jour après jour, jusqu'à la fin. Mais quelle sera la fin?

Aux côtés de cet oiseau absent, endormi ou négligé, se déroule la langue, fabriquée pour cette installation en tissu rouge. Elle sort du mur blanc et descend le long, avant de toucher le sol en vainqueur de la première des grandes frontières qu'il faut franchir : la langue (parlée). Ainsi le silence sera la seule réponse apportée à la toute première question, n'importe laquelle, qui sera posée, induisant ainsi un regard suspicieux, au mieux interrogateur, sur cet oiseau sans plume : Qui êtes-vous? Que faite-vous? D'où venez-vous? Où allez-vous? Evidemment il est impossible de répondre à ces questions, tout simplement parce que l'oiseau juste posé sur son nouveau sol ne chante pas du même chant que l'autochtone. L'oiseau sans plume a une mère, qui demeure de l'autre côté de la mer qui le sépare de l'oiseau local et elle n'est pas la mère de ce dernier. Pourtant tous les deux sont des enfants.

Quel vêtement habillera cet oiseau dénudé par la traversée, par son vol exilique? La langue maternelle est ce lieu que l'on ne quitte jamais, que l'on transporte avec soi : le lieu de l'intime, du familier et du cri primal de la vie. La langue reste dans l'exil le seul rhizome de nos racines qui soit encore plongé dans la terre d'origine et nous y rattache, les autres sont comme nous, épuisés, desséchés et affamés. Si l'on me questionne sur mes origines, les raisons de mon départ, ma destination finale, ma langue est l'unique réponse juste et vraie que je puisse apporter. Je suis ma langue maternelle et c'est elle mon origine. La langue étrangère juste déchiffrée et répétée phonétiquement est comme le chant d'un oiseau pour les humains : incompréhensible. Même si on en lit un jour quelques notes, quand bien même on lirait des portées entières, elle ne portera jamais la chaleur du câlin, l'odeur et le gout qui assouvissent la faim, l'eau qui calme la soif. Pour répondre aux questions sur mes origines, j'ai donc laissé ma langue parler pour moi, faisant ainsi retour et justice à ma mère, porte de mon premier exil et raison de mes recherches : ma mère, mon lieu de départ.

Toute expérience exilique vient brûler les frontières de manière irrévocable et que des cendres naît une identité qui n'admettra pas sans réserve, voire résistance, le retour au territoire. Le sujet exilé peut accepter son nouvel état civil, se couler dans la personnalité prêt-à-porter qu'on lui a préparée, il conserve sur lui la poussière des chemins (NOUSS, 2015, p. 117).

La poussière des chemins demeure sur le corps d'exilé, lui rappelant sa poudre originaire, sa trace. C'est le passage qui se défait et se construit à chaque nouveau pas. La langue maternelle coule en son corps la douceur et le réconfort de savoir qu'il a eu un lieu de départ. Mais, avec la même force, elle lui rappellera l'amertume de l'abandon face au langage étranger. Après neuf ans en France, la langue française met en question mon territoire intime. Je ne sais pas quand je dois partir, ou bien si je dois rester, j'ignore où est mon lieu.

I

Ne plante pas de clou au mur!

Jette ta veste sur la chaise!

Pourquoi prévoir pour quatre jours?

C'est demain que tu rentreras. [...] 
II

Regarde au mur le clou que tu y as planté!

Quand donc crois-tu rentrer chez toi? [...]

(BRECHT, 1966 :131-132, in : NOUSS, 2015, p. 140-141).

Selon Alexis Nouss (2015, p. 141) "si l'inquiétude admet une réalité, puisque l'exilé ne sait pas quand il rentrera, la conviction du retour n'en est pas affectée." Alors que je suis face au tourment du retour qui frappe à ma porte sans que je l'accepte, je me tourne vers mon lieu de départ. Alors je vois mon pays plongé dans une guerre froide, intime et sanglante, dont je me sens prisonnière sans vouloir le devenir. Au milieu de cette tempête, il me faut décrire, tandis que je suis encore en exil, le jour où j'ai rencontré l'artiste Sheila Hicks.

C'était le 21 septembre de 2016, un mercredi après-midi à Paris, dans le quartier du Marais. C'est le jour où je l'ai rencontrée mais elle m'accompagnait depuis déjà quelques jours. Une semaine auparavant, je m'étais en effet rendue au musée Carnavalet pour une visite. Dès l'arrivée dans la cour, je m'étais retrouvée parmi les fils, les tissus et les couleurs de Sheila Hicks. L'œuvre majestueuse s'enroulait entre les buis du jardin, coulait le long des murs et des sculptures. Une longue gorgée de couleurs tombait du haut du pavillon. Cette verticalité colorée a happé mon regard. Entre les tons jaunes et marrons courraient des fils qui m'ont à la seconde immergée dans mes souvenirs lointains, lorsque ma mère faisait ses travaux de crochets. Je me suis intéressée à son travail et suis partie à la recherche d'autres œuvres de l'artiste. J'ai réussi à avoir le numéro de téléphone de son atelier à Paris. J'ai appelé. Elle m'a répondu brièvement et $m$ 'a demandé de la rappeler l'après-midi si je souhaitais la rencontrer. Je ne l'ai pas fait.

Quelques jours après, le mercredi 21 septembre 2016, je suis allée à la galerie Frank Elbaz pour voir encore quelques une de ses œuvres qui y étaient exposées. Soudain, à ma grande surprise, Sheila Hicks est entrée dans la galerie. Une rencontre non prévue! Je lui ai parlé et nous avons programmé un nouveau rendez-vous. J'ai retrouvé dans son regard la douceur de ma mère.

Sheila Hicks est née en 1934 à Hastings, Nebraska. L'artiste américaine a décidé de s'installer à Paris en 1964. Elle a parcouru l'Amérique latine, dont le Brésil. Elle a découvert lors de ce voyage la richesse du savoir-faire des tisserands péruviens, civilisation à l'époque sans écriture.

La rencontre inattendue avec son travail a revitalisé mon passé devenu distant et étranger. Les lignes de ces fils colorés m'ont transportée directement dans mes origines, ont redonné vie à l'étranger qui demeure en moi. Dans son œuvre intitulée The White River (2014), on voit tomber du plafond jusqu'au sol, où elles s'étalent en boucles gracieuses, de longues fibres blanches entrelacées, cascade d'eau souple et douce. Ces fils ont conduit ma pensée sur les rives de mes origines, tressées par les doigts de ma mère et de ma grand-mère, comme l'eau d'une rivière qui suit doucement son destin vers la grande rencontre avec la mer. Dans l'estuaire, les eaux se mêlent en un intense mouvement qui réunit le doux et le salé. 


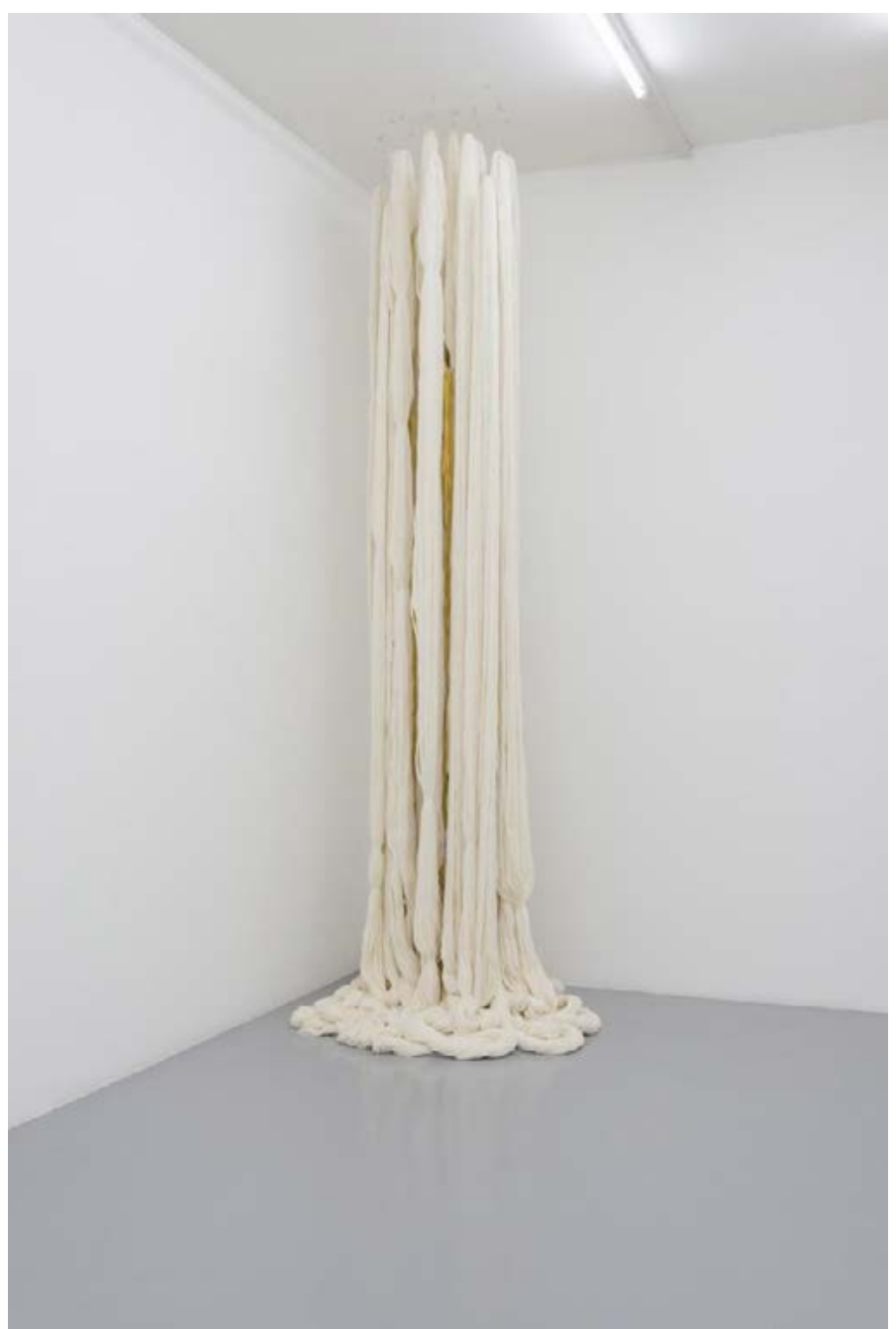

Fig. 6 - Sheila Hicks, The White River, 2014, Ligne, fibre acrylique, 500 x 80 x 80 cm, De 11 Lijnen Foudantion.

Cette œuvre de fibres blanches a recousu mes liens intimes, comme un fil entre ma langue maternelle et ce nouveau langage, le français, étrange et étranger mais nécessaire pour survivre en exil. Le français est la langue dans laquelle Sheila Hicks et moi nous avons pu échanger, chacune avec ses origines et ses accents, américains pour elle, brésiliens pour moi, et toutes les deux en territoire français, loin de nos racines. L'étrange est devenu nécessaire. L'objet provoque la rencontre et l'œuvre l'organise. Quelques semaines après notre rencontre, j'ai reçu chez moi un courrier par lequel elle me proposait une nouvelle rencontre. "Tout ce que je dois dire de la maison de mon enfance, c'est tout juste ce qu'il faut pour me mettre moi-même en situation d'onirisme, pour me mettre au seuil d'une rêverie où je vais me reposer dans mon passé." (BACHELARD, 2008, p. 31).

La langue vécue comme fil qui me transporte vers mon passé, mes origines et ma mémoire, sera maintenant le dessinateur d'une maison imaginaire. Être en exil devient une expérience de l'intime au-dehors, submergé par le manque du dedans. Selon Bachelard (2008, p. 24) " la maison est notre coin du monde. Elle est notre premier univers." Cette maison où je suis née, je l'ai quittée pour faire survivre mon corps blessé. Mais voilà que cette même maison séjourne dans le corps vivant, lui rappelant ses racines, son pays, ses origines et, aussi fortement, la distance irrémédiable créée 
par l'exil. Le corps devient un corps-maison, entouré de la langue nouvellement acquise. Par sa bouche s'exprime son esprit, désireux de se nourrir de ses souvenirs mais aussi de ses mirages.

Face à un retour imminent, le corps laisse surgir le langage de l'obscur, du vécu tué au naufrage du rêve : Tu dois retourner à tes origines, à ton enfance, à ta maison natale, à ton pays! Si tu ne te souviens plus du chemin, tu devras le refaire des pierres de ta souffrance, de ton éternel départ vers un lieu d'accueil où tu pourras reposer dans ton corps et dans ton passé.

Cala-te/Tais-toi (2016), est une photographie que j'avais prise tandis que j'étais sur le point de partir, en position de post-exil. Sur cet autoportrait, je suis avec la bouche ouverte, parlant à mon corps dans ma langue maternelle. Sur cette image en noir et blanc aux contrastes très accentués - l'ombre du départ et la lumière de l'arrivée - j'ai cousu les fils rouges du chemin, soit de l'aller, soit du retour. Le corps fait ce passage, il se met en transit. Avec des fils de laine, j'ai tissé de longues cordes au crochet que j'ai appris de ma mère. Chaque pas du processus de tissage de ces fils revivifiait la langue qui donne toute sa chair à notre nom. L'expérience d'un retour non désiré, d'un départ prochain remettait en question le chemin et tout ce qui avait été acquis lors d'un vécu partagé entre espoir et douleur. J'ai pensé aux objets qui font partie de cette histoire brisée, ceux que j'avais gardés avec moi et qui sont la mémoire source de vie. Ce sont les objets de l'intime, les objets de l'altérité, celle-là même que je tente de cerner dans ce travail.

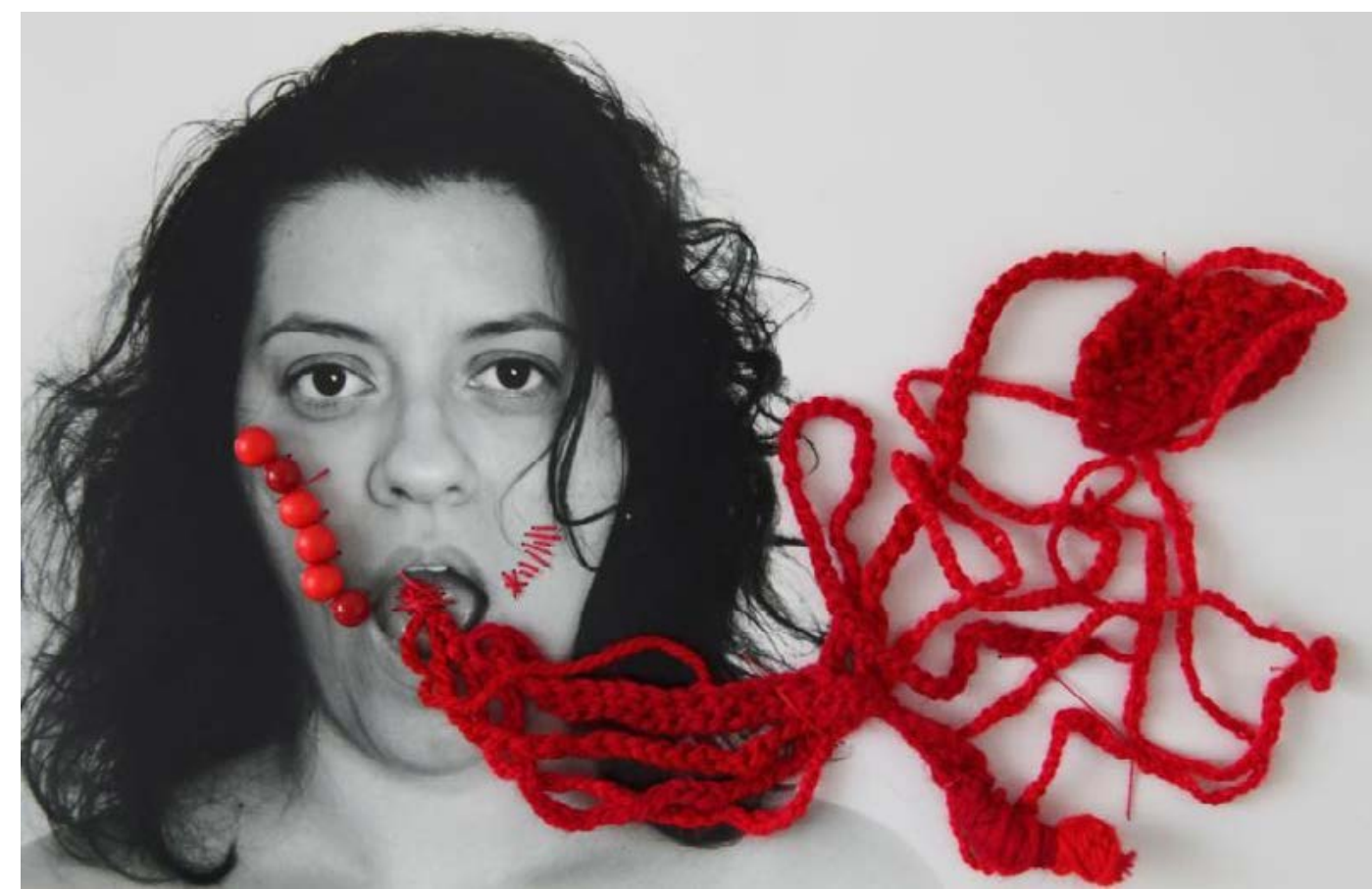

Fig. 7 - Camila Moreira, Cala-te / tais-toi, 2016, photographie, perles, laine, 20 × $30 \mathrm{~cm}$, France.

Quand j'ai reçu de ma mère une collection d'objets personnels, j'ai pris conscience, alors même que j'avais toujours su qu'elle existait, qu'il y avait avec cette collection quelque chose en dehors de moi qui me représentait. Endormie et à fleur de peau de ces souvenirs matériels la mémoire donne corps à l'altérité. La recherche initiée par présence de ces objets avait pour but de débusquer l'altérité intime en son 
refuge. Toujours en mouvement, le corps continue à avancer à la lumière de l'enfance qui l'habite et l'anime. La distance ainsi créée incite à se réfugier en soi-même. À ce moment-là, celui ou celle qui a déjà rompu avec ses racines mais reste attaché à sa langue maternelle ne se trouve nulle part, il est face à son existence, à son altérité intime dont il réalise qu'elle s'enracine dans son enfance.

À partir de ce processus, j'ai revisité ma maison natale désormais imaginaire ou devenue peut-être la maison de l'intime dans laquelle j'irai pour me reposer. Cette maison a quitté le passé et mon pays pour rendre réels mes souvenirs. Bachelard affirme : "L'immensité est en nous. [...] L'immensité est le mouvement de l'homme immobile." (BACHELARD, 2008, p. 169). Cette immensité tissée des rêves et des expériences de mon enfance mais aussi des années vécues au Brésil, avance sur mon corps comme une vague. Cette immensité qui me couv(r)e et dont je reconnais les détails composés par une mémoire consciente devient mon altérité intime. Je vois cette altérité comme un parfum dont le vent va disséminer l'odeur pour qu'il suive son chemin de construction/reconstruction éternelle.

Ma maison natale, revisitée par les pas d'un moi enfantin curieux mais aussi effrayé, mène un combat avec la conscience, avec la trace laissée par le temps sur le corps qui vieillit. Ce processus rend plus réelle que jamais l'inexistence d'une demeure définitive. Je suis celle que je vois au moment de la prise de conscience. Celle que j'étais avant mes souvenirs, celle que je serai après, je m'en rappellerai, peut-être...

L'artiste, comme l'enfant, est passif. L'artiste reste un enfant, qui a perdu son innocence mais qui, pourtant, ne peut se libérer de l'inconscient. Rejouer sa propre terreur est une activité autocentrée et une source de plaisir. Quelques artistes ne font que mimer durant toute leur vie, au lieu de penser. L'expression du soi exclut le savoir (BOURGEOIS, 2000, p. 240-241).

Cet enfant, évoqué par Louise Bourgeois, qui a perdu son innocence sans pouvoir se libérer de son inconscient interroge ma mémoire quant au parcours de mon altérité intime en tant qu'artiste. L'adulte reste un enfant que sa langue maternelle retient vers ses origines. Jusque dans l'exil et le passage du temps, je reste enfant de ma mère et fille de mon pays. Ma maison natale interroge mon passé mais aussi mon présent, dont je reprends à mon compte et m'adresse à moi-même la question respectivement posée par Eliane Chiron : Quelles sont vos origines? - et entendues au chemin - D'où viens-tu? Où vas- tu? Pourquoi es-tu ici?

L'exilé est un étranger par contingence. Lorsque cette étrangeté devient ontologique, lorsqu'elle se détache des conditions empiriques, avec, le cas échéant, transmission vers une ou plusieurs générations, on parlera de post-exil le préfixe marquant une continuité avec transformation, non une rupture. [...] Au demeurant, même pour l'exilé, le retour au pays natal est marqué d'impossible. Est-ce le pays ou l'individu qui a changé? Peu importe. [...] L'exil se nourrit de l'affectivité d'un territoire quitté, volontairement ou non, alors que le post-exil y ajoute le fantasme du territoire perdu (NOUSS, 2015, op. p. 135-136).

Parmi les histoires racontées par ma mère, celles de son enfance se sont entrelacées à mes propres souvenirs. Quand je les entends désormais elles sont incorporées 
dans une seule mémoire, la mienne. Née dans un petit village nommé Douradouquara, ma mère n'a jamais visité le lieu de ses origines, elle ne connait pas sa maison natale. Ses racines se sont plantées jour après jour et à chaque nouvelle demeure dans le terreau d'une enfance pauvre et itinérante. On pourrait presque dire que sa maison natale c'est le déplacement.

Je revisite ma maison natale dans un bonheur intense et intime. À chaque nouveau retour imaginaire, la voix et l'odeur de l'altérité reconstruisent à mes yeux voilés la conscience de mon existence présente. Là nous étions ensemble, dans la coquille; je me revois cachée dans tous les coins imaginables, en train de flâner entre les tiroirs et le nid, entre l'espérance et les rêves de cet enfant que je fus et qui, pour reconnaître qu'elle a eu une maison natale, a dû la quitter.

Le territoire perdu se construit quand le corps commence à sentir le manque du lieu que l'on a quitté. Dans L'atelier rouge (1911), Henri Matisse peint d'un rouge uni l'espace de l'atelier qu'il a créé à Issy-Les-Moulineaux selon son désir et ses rêves de Méditerranée. Est-ce une réconciliation entre le corps et sa conscience? L'atelier est rempli d'œuvres, d'intimité, de travail et de réflexions. La peinture expose les recoins intimes d'un territoire subjectif et le corps de l'artiste circule en son lieu, comme le sang circule dans les veines. En manque d'un lieu d'intimité et de création, je contemple dans mon imaginaire cet espace fantasmé qui abriterait mes œuvres. Mon atelier rouge reste dans l'intime, séparé de ses origines. L'artiste exilé crée d'abord des espaces de création mobiles et éphémères qui l'accompagnent dans ses déplacements.

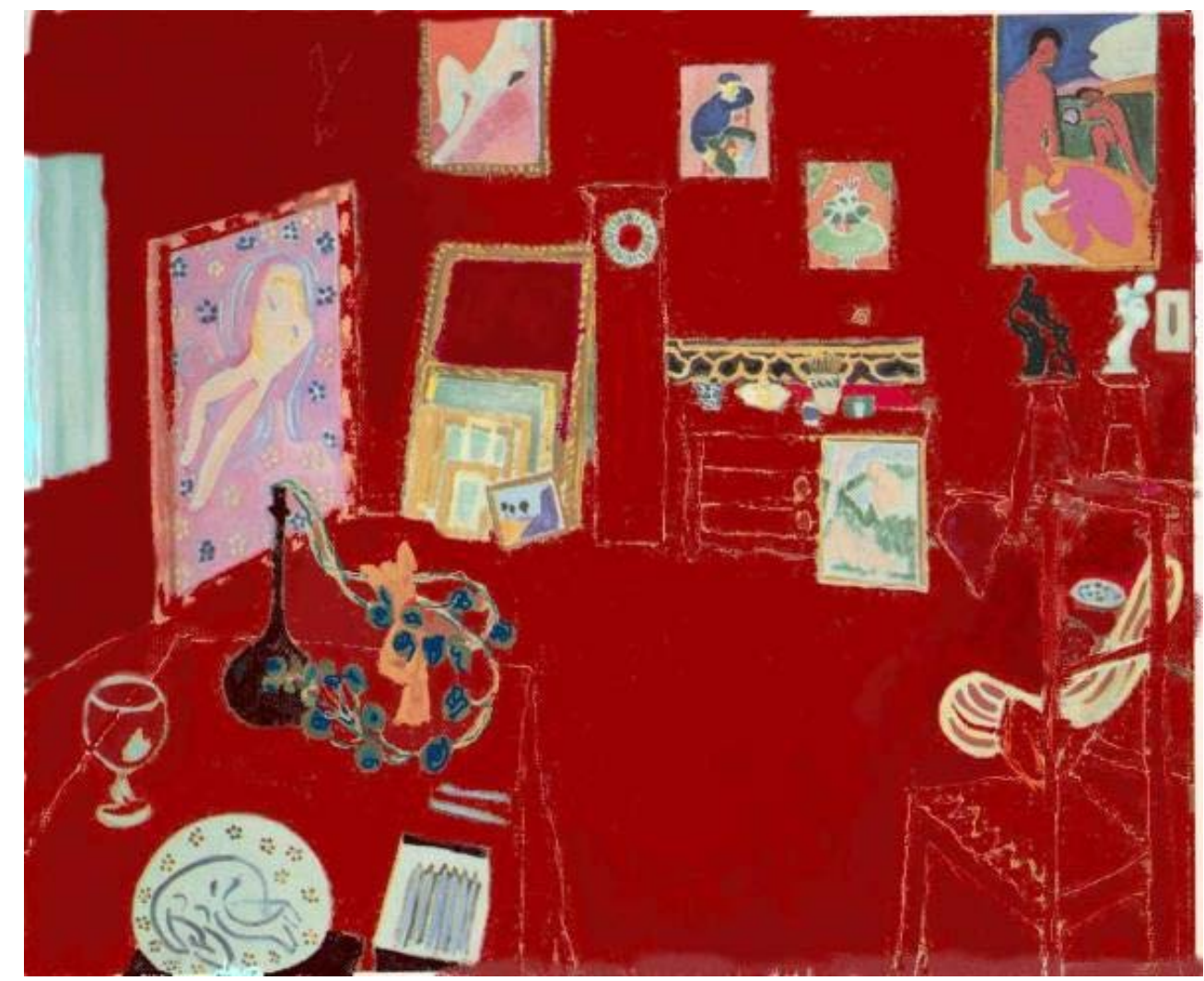

Fig. 8 - Henri Matisse, L'atelier rouge, 1911, huile sur toile, 181 x 219,1 cm, The Museum of Modern Art, New York.

Mon corps d'artiste interroge mon altérité intime et mes origines. L'enfant entrelacé dans les fils revient alors pour recoudre mes liens intimes. Il surgit du dedans comme un vomissement nécessaire, celui que montre l'œuvre Cala-te/tais -toi. 
Les bobines de fils rouges de Red Room (The Child) (1994) de Louise Bourgeois me replonge dans ma maison d'enfance. Mes pas enfantins passaient sur les fils de crochet faits par les mains de ma mère, enroulés par les miennes. Afin de faire exister mon territoire égaré quelque part je transmets aujourd'hui à ma fille cet espace fidèle de l'intime où le travail se mêle au plaisir d'enrouler. Du silence du passé demeure l'altérité, qui sera réveillée par le corps déplacé. Il faut quitter la maison pour la reconnaître, pour en visiter les coins, le grenier, le lit. Il faut être en exil pour se confronter à sa propre réalité intime qui bascule et expulse le corps dans la dimension de la survie.

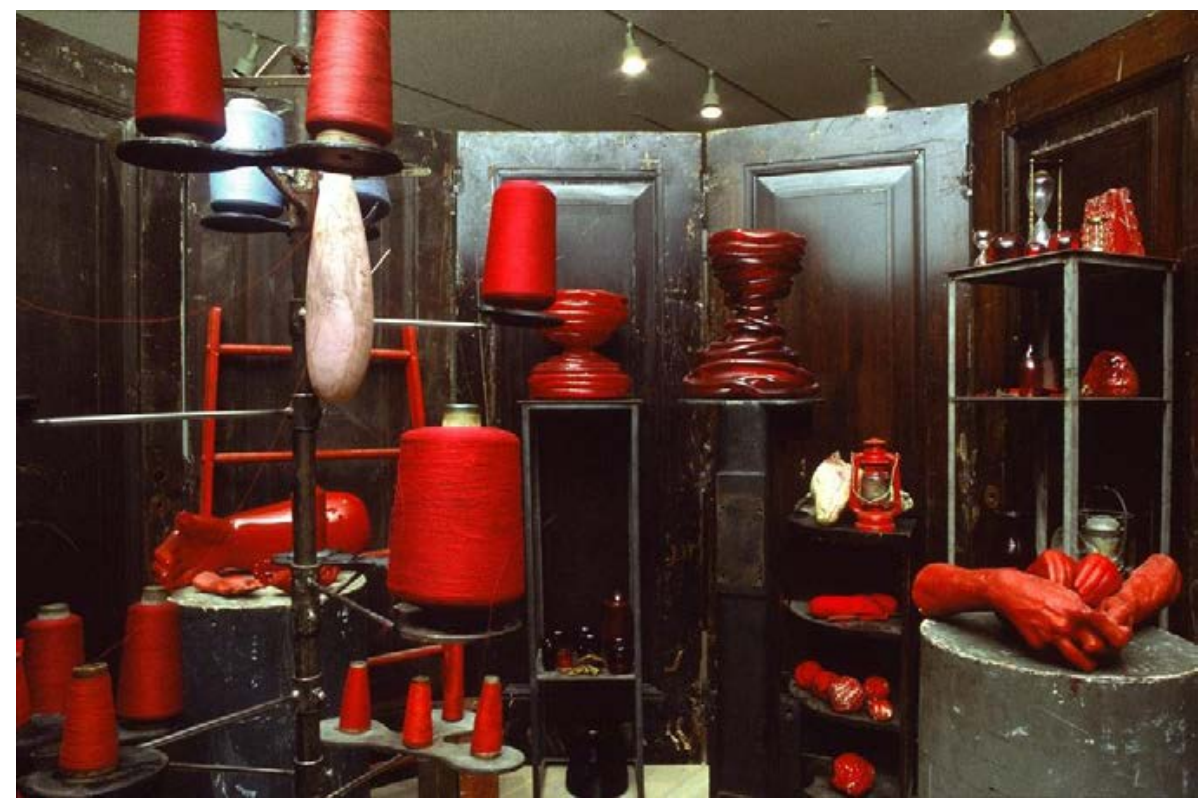

Fig. 9 - Louise Bourgeois, Red Room (The Child), 1994, cotton bobines, fourniture, dimensions variables.

En 1998, je me suis rendue pour la première fois à São Paulo pour visiter la 24e Biennale d'Art, intitulée Biennale de l'anthropophagie en référence au Manifeste du même nom écrit par l'écrivain brésilien Oswaldo de Andrade. Ce fut pour moi une rencontre avec l'intimité. L'œuvre de Cildo Meireles, Desvio para o vermelho (1967-84) m'a férocement happée. La première salle, Imprégnation, est meublée, agencée et décorée comme le serait un salon lambda méticuleusement rangé. À cette particularité près que tout, du sol aux œuvres d'art accrochées aux murs (blancs) se décline en diverses tonalités de rouge, mais absolument et résolument rouge. Ce pourrait être une scène domestique, le salon d'une maison d'enfance dans laquelle plus personne ne demeure à présent mais qu'on revisite dans son intimité. Le chemin de l'œuvre conduit ensuite le spectateur vers une deuxième salle intitulée Environnement. Surgit d'un espace noir intense se dessine, venant vers le spectateur, un chemin de liquide rouge solidifié qui s'est étalé à partir d'une bouteille renversée. La bouteille concentre l'attention par un spot de lumière qui l'éclaire plus que le reste. Enfin, sans nous laisser la possibilité de sortir avant, l'œuvre nous amène jusqu'à une dernière salle intitulée Déviation, qui présente un évier et un robinet duquel coule un liquide rouge ou du sang. 

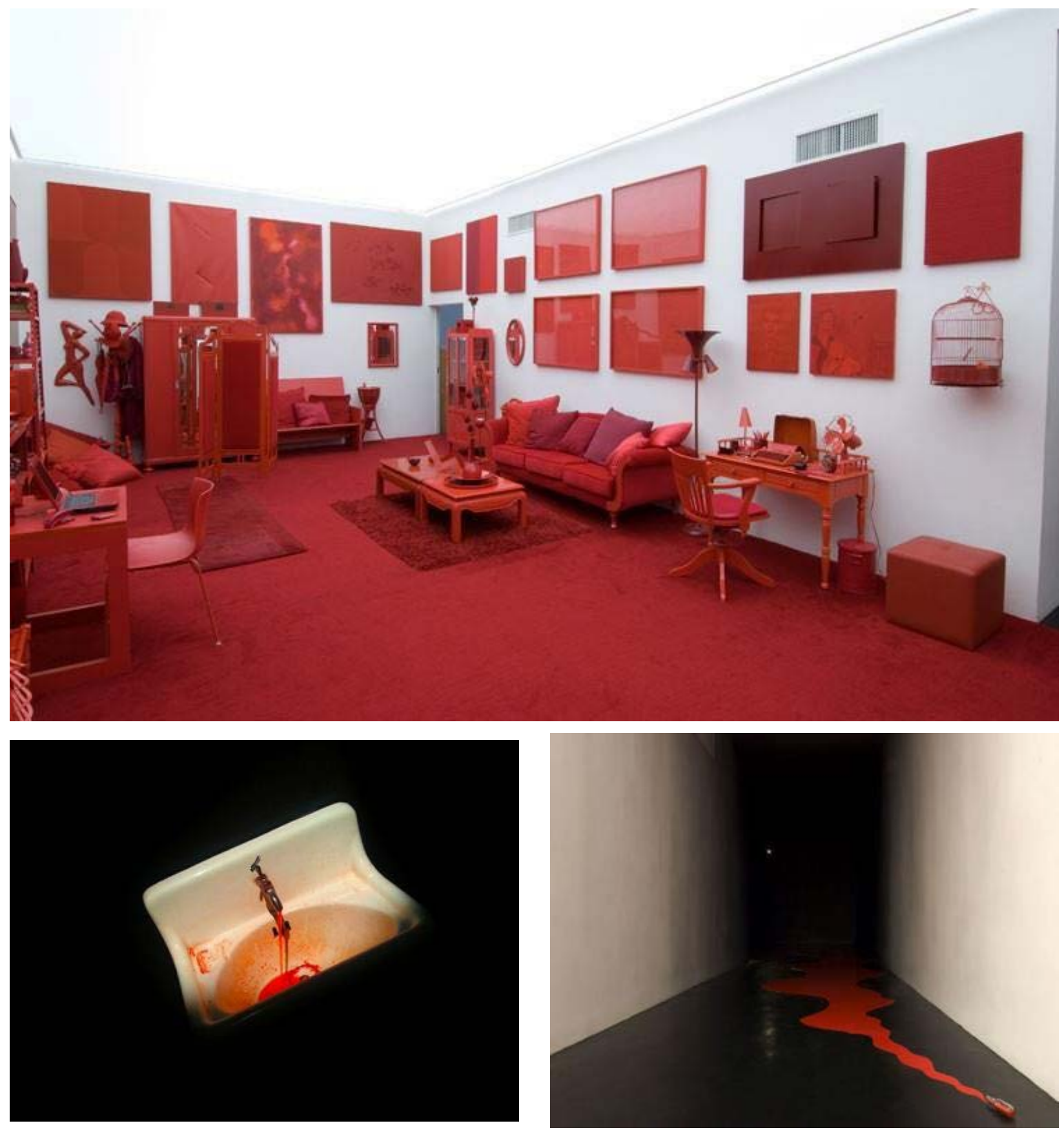

Fig. 10 - Cildo Meireles, Desvio para o vermelho I: impregnaçao, II: entorno, III: desvio, différents matériaux, 1967-84, photo: Pedro Motta.

Ce triptyque dialogue avec ma maison natale, parfois oubliée mais à présent reconstruite loin de son existence concrète. Cette maison est mon corps, où vraiment je me repose, me compose et me refais. Imprégnation est comme un corps-maison, assemblage de vies et de mémoires, d'objets personnels, de souvenirs, de paroles. Une maison intime habillée de rouge, sang-passion et blessure, espoir et douleur. Dans un recoin de cette maison a été imaginé un Environnement en lien avec le vieillissement du corps, comme une maison qui se fait et se défait, souple et malléable pour résister aux impacts du vécu. Tout ça réalise à la fin que tout était une Déviation, parcourue ou regrettée, voulue ou subie, qui nous mène tous également à la mort. Je me suis retrouvé dans un corps-atelier, cousu par des fils de l'enfance dont sort le rouge de ses veines. 
L'œuvre Cala-te/Tais-toi exprime mon regard vis-à-vis du temps présent, auquel je confronte mon passé et mon retour, mon corps de femme et ma voix inaudible. À qui donner la parole? Devant une réalité violente et la violation de droits les plus élémentaires, j'ai quitté mon pays en 2008 pour une Europe qui entrait au même moment dans une phase de crise économique. À présent mon pays traverse un violent conflit de classes, une guerre feutrée et mortelle. Je sens la crise au bout de mes doigts. Tous les territoires sont clôturés. Seule la demeure physique permet le repos. Je reviens à moi-même. Après le départ, la maison d'enfance devient un dessin du désir et de la mémoire ravivée en nous. Reste à savoir où, dans mon corps, se tapit cette maison natale. Où dans moi, habite ma maison d'enfance?

L'artiste portugaise Helena Almeida, fascinée par l'action et le mouvement, amène son corps dans l'espace de création et devient, en même temps que leur créatrice, le sujet de ses œuvres. Son œuvre Écoute-moi (1979), présente deux photos d'elle, en plan américain et de face : sur la première elle porte un foulard noir sur la bouche et regarde l'objectif; sur la seconde ses yeux sont couverts d'un bandeau noir, sa bouche est close. Sur le foulard comme le bandeau il est écrit : Ouve-me (Écoute-moi). Comment entendre ce cri muet venant du corps et de l'intimité d'une femme artiste, lancé à son époque, à ses violences, à ses interdits?

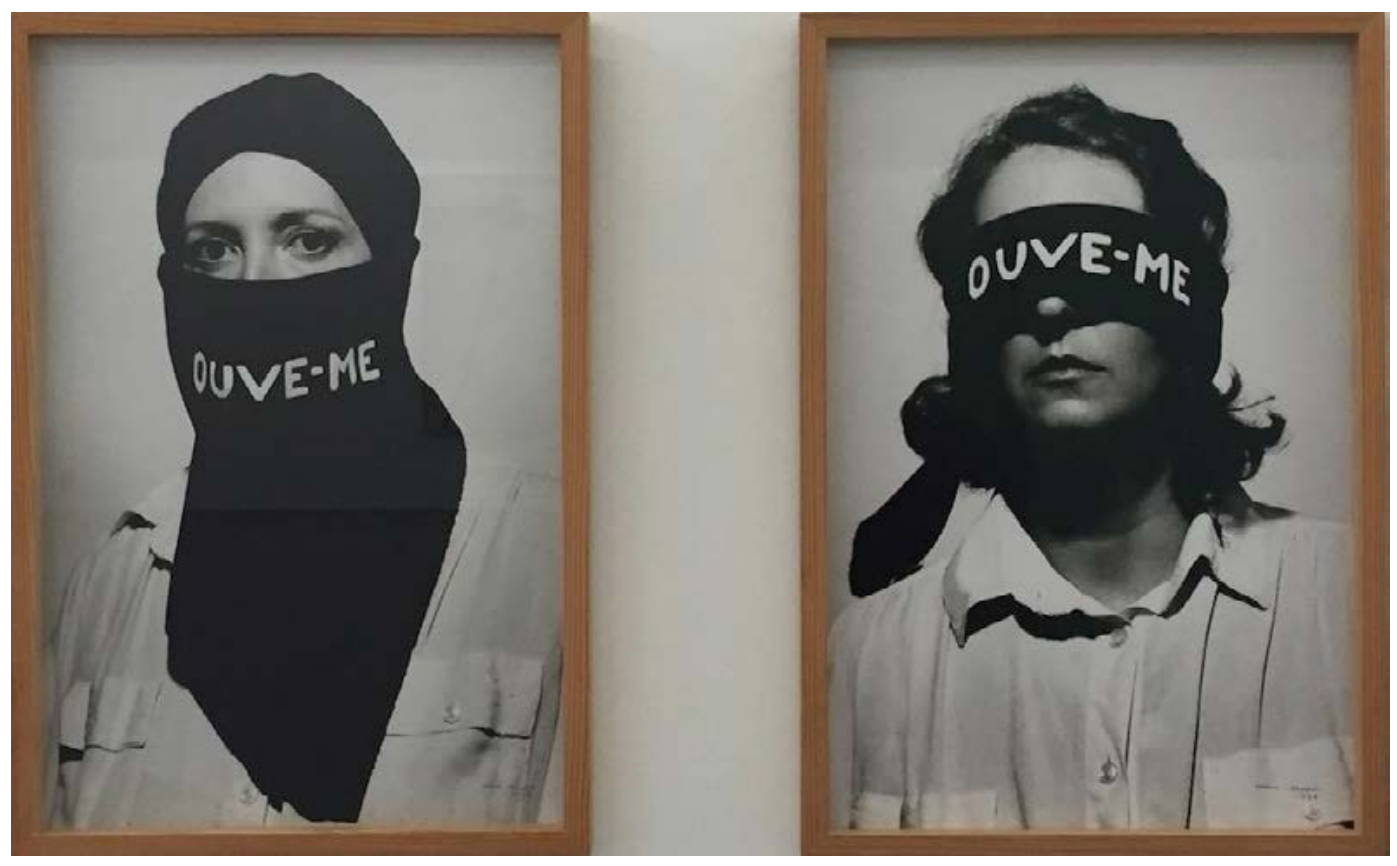

Fig. 11 - Helena Almeida, Écoute-moi, 1979, photo. Jeu de Paume, Paris, France.

Cette œuvre dialogue avec Cala-te, Tais-toi à la manière d'une lutte entre deux injonctions inconciliables : Écoutez! dit la femme, l'artiste, le sujet. Taisez-vous! lui répond-on. Le corps désireux de se faire entendre n'obtient qu'une fin de non-recevoir : silence. Le cri est sourd, la voix muette, la sanglante réalité continue de se dérouler dans le silence des mots bâillonnés. 


\section{Le retour}

"Le] chercheur [...] ne doit considérer un tel fait comme certain que si sa structure la plus intime apparaît assez essentielle pour le révéler comme origine." (BENJAMIN, 1985, p. 44).

D'où viens-je? Pourquoi j'ai choisi de venir ici? Pourquoi je ne suis pas restée dans mon pays? Quand est-ce que je vais y retourner? Où vais-je rentrer?

Si je considère la vie comme un grand voyage, alors c'est un aller sans retour. Envisager de revenir serait prendre un risque inutile car le retour n'existe pas. Il sera toujours un nouveau chemin à parcourir, un instant interrompu, juste le temps de regarder derrière soi : on y verra les choses que l'on a quittées et on réalisera qu'elles aussi ont suivi leur chemin, à leur rythme. Alors je ne reviens pas, je recommence, je quitte à nouveau. Est-ce que je reconnais le chemin traversé? Ici ma mémoire me trahit : tout y semble figé sauf moi. La mémoire, infidèle à la réalité, n'a gardé des choses que leur aura. "Qu'est-ce que l'aura? L'aura est l'apparition d'un lointain aussi proche soit-il." (BENJAMIN, 2011, p. 53).

Dans ce proche pourtant si lointain j'ai déambulé parmi mes racines, ma genèse, mon hérédité. J'ai trouvé encore des blessures et, bien sûr, du sang. J'ai trouvé l'indienne éloignée mais aussi touchante. Sur mon visage, sur mon corps, sur mon âme j'ai mis du rouge. Peut-être cette indienne cachée dans mon corps, aimait-elle aussi le rouge? Je suis aussi allée dans mon enfance, à côté des jouets et de cette collection gardée précieusement, qui devait me représenter. Je me suis rendu compte que cette enfance est encore vivante, en exil avec moi, qu'elle veille sur moi. J'ai rencontré les blessures, celles qui m'ont poussée à partir. Elles restent là, moins à vif mais toujours comme une marque au fer rouge qui n'en finit pas de cicatriser. Je n'ai pas essayé de les guérir. Je les observe à l'instant. J'ai réalisé cet examen rétrospectif en progressant pas à pas entre les souvenirs dans le but de trouver une réponse à l'éventualité et l'opportunité de mon départ. Ce faisant, j'ai pris conscience de la présence de l'autre dans mon corps.

J'avais besoin de faire une œuvre pour rétablir le sens du commencement. Rappelle-moi à moi-même est envisagée comme un nouveau point de départ vers l'origine rêvée.

En avril 2016, j'ai demandé à dix-sept personnes, entre la France et le Brésil, de m'écrire une lettre manuscrite et de me l'adresser, à mon domicile français, par voie postale. Cette lettre devait répondre à deux questions :

1. Qui suis-je pour toi?

2. Comment étais-je la dernière fois que nous nous sommes vus? 

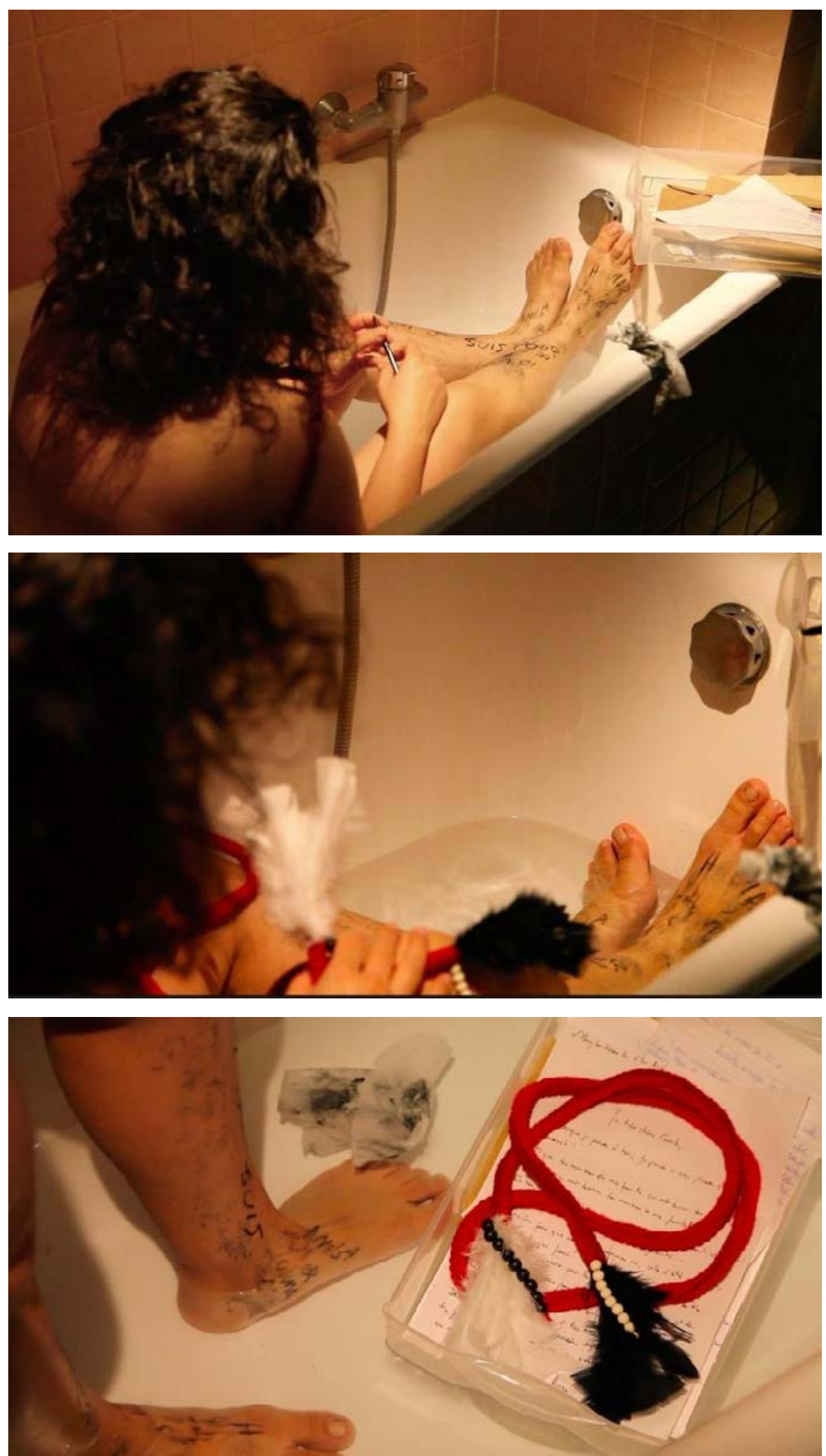

Fig. 12 - Camila Moreira, Rappelle moi à moi-même, 2016, vidéo, 7’00, France.

Huit réponses sont arrivées, échelonnées jusqu'en août 2016, échéance que j'avais choisie et imposée. Des autres expéditeurs potentiels je n'ai rien reçu (ou rien ne m'est pas parvenu). Huit lettres écrites et reçue comme les huit ans que je venais de passer en France. Neuf lettres manquantes comme neuf mois de grossesse. Une belle coïncidence quant à l'attente! 
La surprise est arrivée avec chaque enveloppe. J'attendais tous les jours le passage du facteur, guettant ma boîte aux lettres. Chaque lettre, chaque sourire exprimé dans les mots m'ont ramenée à moi. J'ai touché mon corps d'enfant. J'ai revisité mon pays. J'ai senti l'odeur de ma maison natale, des jours de pluie et de peur, des jours de joie et d'attente. Grâce à ce retour frayé parmi les mots, j'ai habité à nouveau ma maison d'enfance. Je suis revenue au Brésil, avant l'exil. Je m'y suis revue, pleine d'enthousiasme, tenant entre mes mains le billet « aller » pour ce voyage sans retour qui s'appelle la vie... Chaque lettre a été numérotée et archivée avec sa date de réception par ordre d'arrivée, sur une échelle allant jusqu'à 17.

Il fallait construire l'œuvre qui serait ce demi-tour fait sur moi-même pour prendre conscience du passé, du chemin parcouru, et pouvoir les affronter. J'ai lu et relu plusieurs fois chaque lettre. J'ai réalisé à quel point le regard de l'autre était important dans la construction de soi et à quel point il était devenu vital pour moi de relier tous ces morceaux de moi, vus d'ici et de mon pays.

La vidéo a été réalisée selon l'angle du voyeur qui observe une scène. J'ai positionné la caméra à la diagonale. J'ai demandé à mon mari de faire la captation car je me mettais en scène. Posée sur moi et mon corps comme le regard de l'autre, la caméra deviendrait surveillance inaperçue, cet autre qui me regarde mais que je ne vois pas. Il me surveille et j'en ai bien conscience mais je ne peux que rester à ma place. C'est un corps d'enfant, nu, que j'ai assis dans l'eau de la baignoire en même temps que mon corps nu de femme adulte. Cette eau qui a bercé le fœtus dans l'utérus sépare aujourd'hui l'enfant de sa mère, elle l'éloigne, liant la conscience de l'enfant à ses origines et sa mémoire à sa genèse. Comme Marat à son dernier soupir, mon corps est assis dans la baignoire pour lire les lettres. Sur mon dos et enroulée autour du cou, il y a la corde de la vie déterminée par le passage du temps. Elle entoure mon cou comme une veine remplie de sang. À chacune de ses extrémités pend le mélange de la vie et de la mort, sans interruption entre les deux, sans que ni le début ni la fin soit fixé par avance.

Chaque lecture de lettre, chaque mot composerait un morceau de mon histoire, de ma pré- et posthistoire selon Benjamin. De chaque lettre j'ai décidé de choisir quelques mots en même temps que je la lisais et de les écrire sur mon corps, sur ma peau, surface de contact entre le regard de l'autre et le noyau intime. Il fallait faire un choix, une sélection des mots les plus importants, les plus frappants. Ce serait ceux qui auraient été, pensés, assumés et acceptés comme moi vue par l'autre et reconnue par mon moi. J'ai les donc écrits au crayon gras sur mes jambes et, après avoir fini de lire la lettre qui les contenait, j'ai les effaçais avec un chiffon mouillé en prenant soin de laisser une trace. J'ai volontairement choisi la partie du corps qui permet la marche et le déplacement. J'assume ces mots, ces verbes, ces idées, ces regards sur moi de l'autre qui me surveille.

Sur la vidéo qui capte cette performance on entend en continu le bruit de la mer, comme lors d'une traversé, avec le chant des mouettes qui accompagnent le navire. On entend aussi la phrase : Qui je suis pour toi?, question à laquelle un bout de réponse est arrivé par chaque lettre, chaque jugement, chaque non-dit, chaque lettre qui n'est pas arrivée, chaque méprise, chaque fierté, chaque amour et chaque haine. À la fin, le souffle de la mère, les battements de son cœur, tout ce qu'entend le fœtus dans la matrice, vient clôturer le désir de me rappeler à moi-même qui suis-je? 
Cette phrase intime, qui marque l'attente de l'autre et de son avis pour me reconnaître décomposée en chacun de ses cinq composants, permet de ramifier encore les questionnements de départ.

Qui : qui est à rechercher, l'objet ou le corps? Qui est l'exilé? Qui va le définir? Qui est toi? Qui est moi? Qui nous sépare? Qui définit le territoire et la frontière? À qui appartient-il? Qui doit partir? Qui est arrivé?

Je : je ou moi? Comment le reconnaître? Est-ce qu'il faut le reconnaître? Pourquoi est-ce que je le cherche? Pourquoi le cherche-t-on? Je-objet ou je-chose? Ou bien serait-il je-chose/objet?

Suis : être, suivre, arriver, partir car il va arriver. Je suis et toi suis aussi dans mon moi. Est-ce que l'exilé suis/est lui-même? Ou bien serait-il seulement il, en exil, rien d'autre? Un numéro, un migrant, un corps errant, un corps hors ses origines. Mais quelle origine? Quelle origine va déterminer qui je suis ou ce que je suis?

Pour : la préposition envoie vers deux directions opposées : ce que l'on fuit et ce que l'on cherche, «à cause » et « en vue de », le passé et l'avenir. J'ai quitté pour partir, pour survivre, pour reconnaître, pour être accueillie, pour vivre.

Toi : me voilà enfin arrivée jusqu'à toi, qui commences le discours de mon moi, toi que j'interpelle, que je cherche, vers qui je marche. Toi, le lieu d'accueil, toi la frontière, toi la barrière, toi le juge, toi le point du retour, toi le nouveau départ, toi le départ. Toi comme un miroir.

Rien n'est plus proche de la quête du départ que le doute car « qui suis-je pour toi? » entraine l'attente, l'incertitude, l'espoir, la recherche, la rencontre. Alors, pourquoi partir? J'avais besoin de garder de cette vidéo quelques moments fixés dans une photographie. Cela m'a permis de donner un lieu et un temps à chaque lettre reçue. J'ai donc mis, pour chacune des huit lettres, huit photos à moi, désormais attachées et fusionnées à l'image qu'elles me renvoyaient de moi.

Tandis que la pensée et la question d'un retour continue de me tarauder, la France, mon territoire d'accueil, continue d'être témoin et acteur du drame migratoire qui se joue aujourd'hui, en 2018 et depuis plusieurs années maintenant. Des exilés en péril, des migrants de passage, des émigrés de retour sont échoués ou en transit sur le sol français et les questions qu'on leur pose résonnent comme un écho à mon oreille. Je me demande pourquoi partir, puisque à chaque frontière du vécu on doit se reconstruire comme un nouveau-né.

Alors que j'étais en France, j'ai à nouveau eu des échos de mon pays grâce à l'art. Le 19 novembre 2016, je suis allée voir, l'exposition L'Atelier Tropical-Jean-Baptiste Debret, à la Maison de l'Amérique Latine, à Paris. Parmi les 74 œuvres/aquarelles présentées, le regard et l'œuvre de Jean-Baptiste Debret m'ont encore mise en contact avec l'intime en moi et $\mathrm{m}$ 'ont permis de continuer à répondre à la question de mes origines et du lieu quitté. Debret est un peintre français qui croyait au départ, comme l'explique Jacques Leenhardt, commissaire de l'exposition, s'être exilé dans une terre lointaine et exotique. 


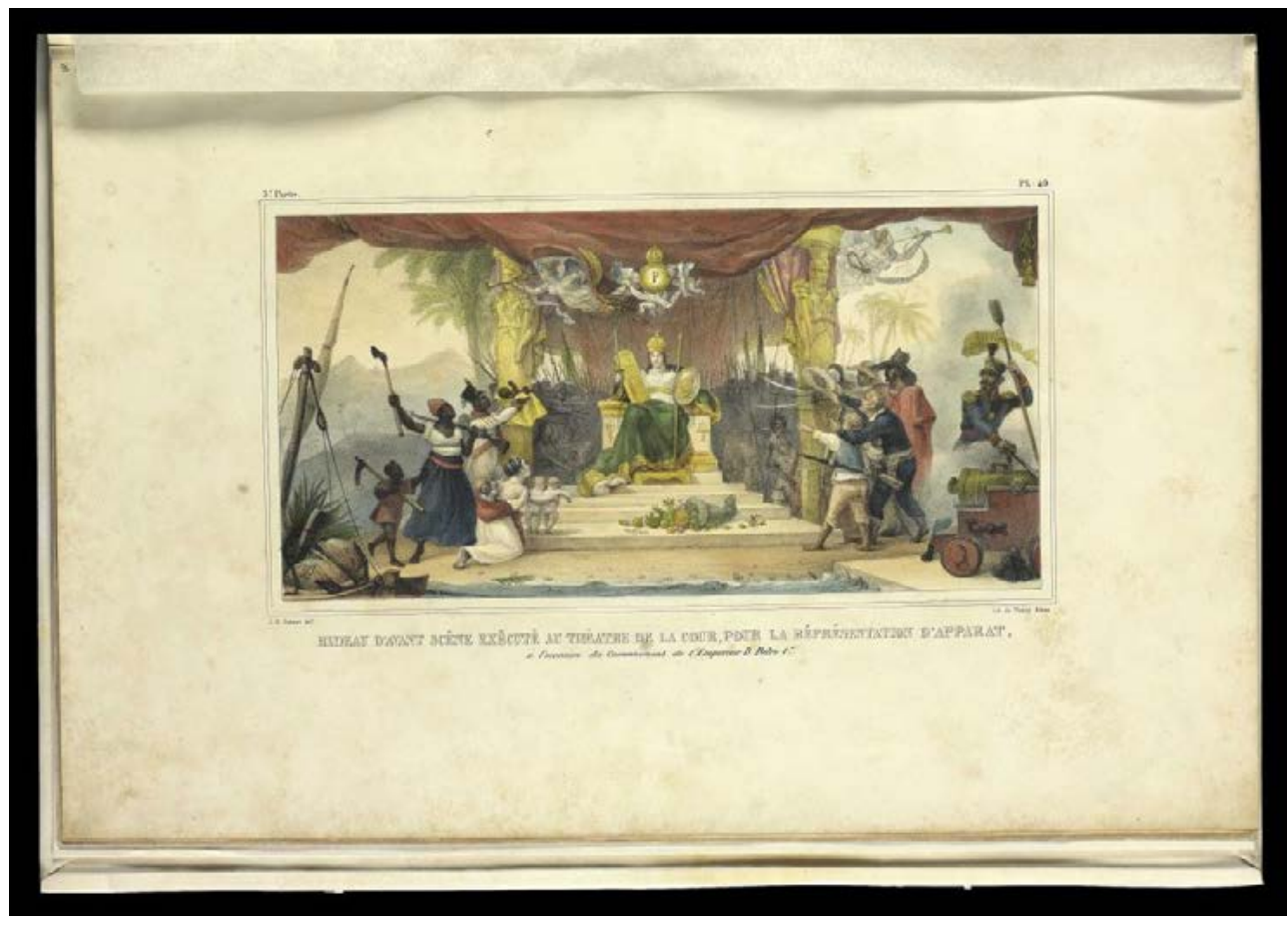

Fig. 13 - Jean-Baptiste Debret, Rideau d'avant-scène exécuté au théâtre de la cour pour la représentation d'apparat, 1834-1839, lithographie. Maison de l'Amérique Latine, Paris, France.

Une fois sur place il participé au dévoilement d'une nation multiraciale, encore dominée par l'esprit colonial et l'esclavage. Une de ses œuvres marquantes quant à la construction de l'image de la nation brésilienne est Rideau d'avant-scène exécuté au théâtre de la cour pour la représentation d'apparat. Une femme blanche assise sur un trône au centre du tableau tient les instruments du pouvoir face à son peuple, entre les esclaves noirs et les fruits de leur travail d'une part, les colons, les propriétaires terriens et l'armée d'autre part. Derrière elle, comme une menace sourde, les peuples autochtones. Les composantes d'un Brésil inégalitaire et divisé sont toutes là. Mais mon attention est surtout attirée par la représentation de la mer tout en bas de l'image. Elle est en mouvement, mais reste au bord, comme quelqu'un qui contemplerait de face la mise en scène destinée à l'Europe, ce portrait très composé de la nation colonisée. Dans d'autres tableaux, Debret représente aussi la vie quotidienne des esclaves, les blessures mais aussi le paysage, la nourriture, les habitudes. La mer est alors présente et souveraine, affichant la frontière et traçant la limite entre notre identité réelle et celle qui a été imposée sur nos épaules.

La mer, celle qui sépare et lie. L'eau qui nous berce et nourrit dès avant le premier exil, qui compose la plus grande part de notre corps, celle dont on a besoin pour vivre, celle enfin, à laquelle on retourne quand nos cendres ont atteint les tréfonds de la terre et ses nappes d'eau souterraines. La mer fait frontière, elle a été le chemin des découvertes, des échanges, des commerces les plus abjects, le terrain des guerres mais aussi la voie de la survie, d'un nouveau départ, des retrouvailles. Aujourd'hui, la mer Méditerranée est un vaste cimetière au fond duquel des hommes, des femmes et des enfants sans destin attendent une sépulture qui ne leur sera jamais faite. La mer amère, la mer mère. 
J'ai trouvé dans la vidéo La mer d'Éliane Chiron une approche essentielle à ma recherche. Cette vidéo de 2'09 touche mes souvenirs. J'ai pris plusieurs pictogrammes de sa vidéo en écoutant le son émis par la mer, où l'artiste nous fait merveilleusement toucher l'altérité. À chaque photo prise venait de se créer une nouvelle image en même temps que la vidéo se déroulait sur l'écran.

Que ce soit à partir de photos ou à partir de la vidéo, le mouvement d'un troisième parcours s'accomplissait : le mouvement émis par le souvenir. J'ai reçu cette vidéo, douce et frappante en même temps, de la mer agitée, comme une scène photographique. En y associant le son, Éliane Chiron a créé, en tonalités de rouges mêlées aux couleurs originales de la mer, le mot, non-dit, la scène cachée, le mouvement vers l'intime parcouru par le corps qui regarde l'œuvre ainsi que par le sujet qui cherche son altérité dans l'image. À propos de son œuvre, elle écrit :
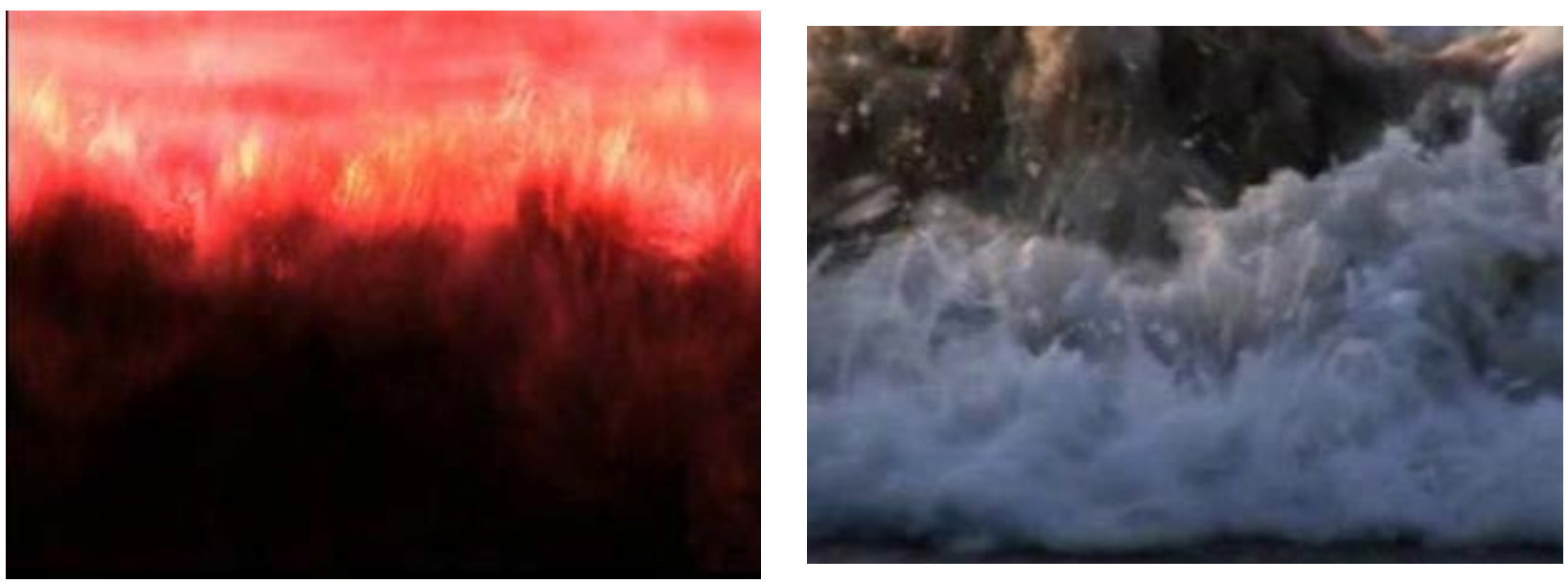

Fig. 14 - Éliane Chiron, La mer, vidéo numérique, 2'09 en boucle, 2008 @Éliane Chiron (Montage, traitement de son et image, Hervé Penhoat).

Le monde serait inhabitable. On pourrait seulement habiter le vide constituant des images que l'on fait, rempli du bruit confus de la mer, des tempêtes, des guerres, du sang. La mer. J'ai filmé l'Atlantique en France, face au soleil couchant, à marée haute, à l'approche de Noël 2007, les pieds dans l'eau glacée, au plus près des déferlantes, faisant corps avec la vague et la caméra. Au montage, j'ai voulu que la mer soit comme un tsunami, menace lente, palpable, venue du fond des temps, pourtant si proche, chaque seconde, migrant sur le mur, sur l'écran. Le rouge est au début. D'une vidéo à l'autre. L'océan migre entre France et Brésil, entre guerre mondiale et mémoire de dictature : grâce au numérique, puissance mutagène, la haute marée de Noël mute en vagues humaines et inversement. J'habite la déflagration de l'image, au point où l'écume devient la neige, le feu le sang, le jour la nuit, quand à midi, à toute volée, déferlent les revenants. Ceux du Vel' d'Hiv de juillet 1942, tout près d'ici? Ces revenants sont mes représentants. Parfois, comme eux, je me sens invisible aux autres, et parfois trop visible. C'est pourquoi peut-être, en tant qu'artiste, je vois si bien l'invisible. Serais-je comme toutes ces femmes du film Volver d'Almodovar? Mutantes. Hors la loi $^{2}$.

Où sont placées mes expériences? Comme la mer d'Éliane Chiron, l'aller-retour des eaux qui circulent dans le corps mirage supposé être vu de loin, est comme le sang que nous nourrit. Tout ça bouscule et j'ai fini par prendre conscience de mes expériences liées à mon corps errant, migrant, exilé et désirant. Un corps d'artiste. 
L'œuvre nourrit les réponses. Comme la mer n'a ni début ni fin, on n'en connaît que la rive de sable où on se place pour la contempler. L'eau qui sépare et qui lie est aussi à l'intérieur de la terre, mais également dans mon corps. Le chemin vers l'origine est livré par le corps, dont les relations qu'il entretient avec l'autre sont une composante essentielle. Ces relations donnent forme à l'enfance, quand on peut librement les tisser où le vent conduit le corps. C'est à partir d'une question sans réponse exacte, comme un bord de mer, que les expériences vécues, et gardées en mémoire seront admises en guise de réponse. La question m'a été posée de façon théorique mais la réponse n'est intelligible que dans l'œuvre. Car seul le déplacement hors de soi-même, le décentrement, peut permettre d'accéder à ses racines cachées.

En quoi le parcours d'un corps revivifié comme artiste peut-il générer d'autres processus créateurs? Le désir de créer revisite toujours une mémoire sauvegardée soit dans les objets, soit dans l'imagination. La mise en lumière de ce processus apporte une réponse à l'une de mes questions d'enfant : comment peut-on reconnaître un sujet à partir de ses objets gardés? Dans quel vide restera mon corps quand il ne vivra plus que dans la mémoire? Si cela entraine la prise de conscience que tout est passé et que seul le présent existe, doit-on chercher le point de départ ou le déplacement? Comment savoir d'où je suis venue, où je vais? Ces réponses appartiennent à la mer, au mouvement, au devenir, aux souvenirs, aux choses que l'on a quittées.

Ainsi l'œuvre est-elle une lecture du temps, une nécessité impérieuse du présent : je dois le faire! Seule l'image vue ou sentie peut donner une idée de la réalité. Le reste ne sera que discours.

L'œuvre Rappelle-moi à moi-même interroge l'identité, la mémoire, la collection, l'objet gardé, l'histoire. Les mots retranscrits sur mon corps comme un environnement iconographique ont fusionné pour rappeler comment l'image créée peut être un véhicule de l'imaginaire. L'objet se tient à la croisée des deux faces du sujet, entre sa part sociale, collective et partagée d'une part, et le reste non-partageable, individuel, qui appartient à ses souvenirs intimes.

Il y en a qui croient trouver la clé de leur destin dans l'hérédité, d'autres dans l'horoscope, d'autres encore dans leur éducation. Moi-même je crois que je trouverai maintes lumières sur ma vie ultérieure dans ma collection de cartes postales illustrées (BENJAMIN, 2011, p. 170).

La clé du destin est potentiellement attachée à l'objet, au corps, à la collection, à la mémoire. On a tous des objets personnels quasi fétichisés car en nous demeurent l'exil, le déplacement et l'espoir. Nous sommes tous des migrants dans le présent, chercheurs-arpenteurs du territoire intime. Le voyage de retour sera le voyage du départ et le lieu d'accueil toujours un nouveau lieu de départ.

\section{Conclusion}

Mon corps à la recherche de sa libération s'est ainsi exilé, la douleur exposée a engendré un déplacement du territoire. Il est devenu exilique et il est déplacé autour de sa propre étrangeté. Il est son origine et son départ, il souffre de son parcours et il devient son lieu. Mais j'avais quitté mon pays pour conquérir l'étrange à l'étranger 
sans savoir que l'unique étrangère c'était moi-même. Après la traversée des eaux, après le voyage intime dont tout exilé fait l'épreuve, j'ai découvert que le voyage serait sans retour, sans lieu, au milieu de nulle part. Il fallait laisser couler dans la mer le rouge étouffant : il fallait partir. Les migrants, les exilés, les expatriés, tous ces corps en fuite, pourquoi partent-ils? Peut-être déplacent-ils leur corps pour changer de lieu ou peut-être changent-ils de lieu pour récupérer leur corps... La fuite d'un corps traumatisé, livré à l'inconnu de l'exil, reste agressé par son corps brisé, coupé de son passé et ouvert à sa déchéance, à son devenir, à son territoire perdu. Ainsi exilée à moi-même, revisité et envahie par les ténèbres j'ai tenté par mes œuvres de créer un corps réflexif sur lequel je puisse inscrire le lieu quitté, le vécu ou encore le passage du temps. L'artiste est un migrant et un exilé, celui qui a quitté son territoire pour en rejoindre un autre, vers l'éternelle voyage de retour.

\section{Références}

BACHELARD, G. La poétique de l'espace (1957). Paris : Puf, 2008.

BAQUÉ, D. Anselm Kiefer. Entre mythe et concept. Paris : Éditions du Regard, 2015.

BENJAMIN, W. Enfance Éloge de la poupée et autres essais. Paris : Rivages Poche, 2011.

BENJAMIN, W. L'origine du drame baroque allemand. Paris : Flammarion, 1985.

BERNADAC, M-L.; STORSVE, J. Louise Bourgeois. Paris : Centre Pompidou, 2008.

BOUHOURS, J-M. Anselm Kiefer. Paris : Centre Pompidou, 2015.

BOURGEOIS, L. Destruction du père, Reconstruction du père. Paris : Daniel Lelong éditeur, 2007.

BOURGEOIS, L. Moi, Eugénie Grandet, précédé d'un essai de Jean Frémon. Paris : Le promeneur, 2010.

NOUSS, A. La condition de l'exilé. Paris : Éditions de la maison des sciences d'homme, 2015.

NOUSS, A. Paul Celan. Les lieux d'un déplacement. Paris : Le bord de l'eau Éditions, 2010.

Disponível em: <http://www.elianechiron.com/La_mer.html >. Acesso em : 01 avril 2018. NUSELOVICI (NOUSS). A. Exiliance : condition et conscience, FMSH-WP-2013-44, septembre 2013, p. 4. Disponível em: < halshs-00861246 https:// halshs.archives-ouvertes.fr/halshs-00861246>. Acesso em: 30 mai 2018. 